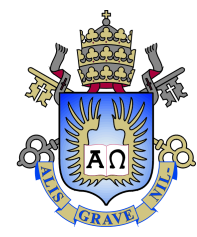

Samuel Pacitti Gentil

\title{
Aspectos geométricos de poligonais genéricas: curvatura total e convexidade
}

Dissertação de Mestrado

Dissertação apresentada como requisito parcial para a obtenção do grau de Mestre pelo Programa de Pós-graduação em Matemática da PUC-Rio .

Orientador: Prof. Marcos Craizer 


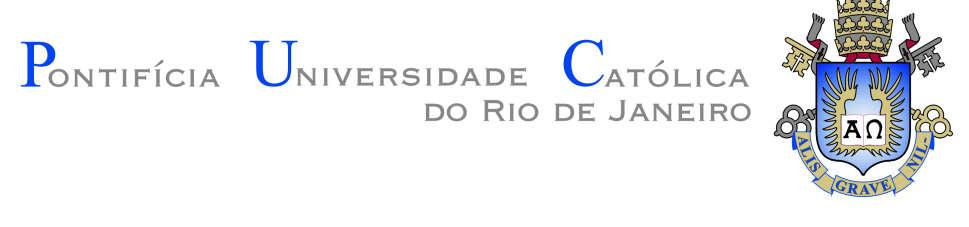

Samuel Pacitti Gentil

\title{
Aspectos geométricos de poligonais genéricas: curvatura total e convexidade
}

Dissertação apresentada como requisito parcial para a obtenção do grau de Mestre pelo Programa de Pós-graduação em Matemática da PUC-Rio . Aprovada pela Comissão Examinadora abaixo.

\author{
Prof. Marcos Craizer \\ Orientador \\ Departamento de Matemática - PUC-Rio
}

Prof. David Martínez Torres Departamento de Matemática - PUC-Rio

Prof. Sinésio Pesco

Departamento de Matemática - PUC-Rio

Profa. Maria del Carmen Romero Fuster Departamento de Matemática - Universidade de Valencia 
Todos os direitos reservados. É proibida a reprodução total ou parcial do trabalho sem autorização da universidade, do autor e do orientador.

\section{Samuel Pacitti Gentil}

Graduou-se em Matemática-Licenciatura pela Universidade Federal Fluminense (UFF).

Ficha Catalográfica

Pacitti Gentil, Samuel

Aspectos geométricos de poligonais genéricas: curvatura total e convexidade / Samuel Pacitti Gentil; orientador: Marcos Craizer. - Rio de janeiro: PUC-Rio, Departamento de Matemática, 2020.

v., 61 f: il. color. ; $30 \mathrm{~cm}$

Dissertação (mestrado) - Pontifícia Universidade Católica do Rio de Janeiro, Departamento de Matemática.

Inclui bibliografia

1. Matemática - Teses. 2. Poligonais genéricas;. 3. Curvatura total;. 4. Grafo de Maxwell.. I. Craizer, Marcos. II. Pontifícia Universidade Católica do Rio de Janeiro. Departamento de Matemática. III. Título. 


\section{Agradecimentos}

Gostaria de agradecer ao meu orientador, Marcos Craizer, pelo tempo dedicado, pela disposição e alegria em discutir matemática, pela paciência em me sanar as dúvidas que surgiram ao longo do trabalho.

Agradeço a David Martínez Torres, Sinésio Pesco e Maria del Carmen Romero Fuster por terem aceitado particar da banca, e que contribuíram, de modos diferentes, para a realização deste trabalho.

Agradeço à minha família, que me apoiou e estimulou ao longo dessa caminhada, tanto emocional, logística como financeiramente.

Agradeço aos meus amigos, inclusive aos que conheci na vida acadêmica. Sem estes a Matemática não seria tão interessante.

Agradeço também à PUC-Rio e ao Departamento de Matemática, pela oportunidade de estudar em um ambiente agradável e propício à discussão de ideias matemáticas, tanto com professores como com estudantes. Agradeço aos professores pelo conhecimento ensinado, e aos funcionários técnico-administrativos que sempre me auxiliaram na dificuldades burocráticas e técnicas.

O presente trabalho foi realizado com apoio da Coordenação de Aperfeiçoamente de Pessoal de Nível Superior - Brasil (CAPES) - Código de Financiamento 001, e com apoio da FAPERJ. 


\section{Resumo}

Pacitti Gentil, Samuel; Craizer, Marcos. Aspectos geométricos de poligonais genéricas: curvatura total e convexidade. Rio de Janeiro, 2020. 61p. Dissertação de Mestrado - Departamento de Matemática, Pontifícia Universidade Católica do Rio de Janeiro.

O objetivo deste trabalho é o de estudar propriedades geométricas de curvas poligonais genéricas. Inicialmente abordamos resultados clássicos para curvas quanto à sua curvatura total no caso discreto e discutimos aqueles pertinentes a nós poligonais. Também é feito o estudo do Grafo de Maxwell para poligonais. No caso, temos uma interessante relação entre a natureza do grafo quanto ao seu número de componentes e à condição de a poligonal ser ou não convexa.

\section{Palavras-chave}

Poligonais genéricas; Curvatura total; Grafo de Maxwell. 


\section{Abstract}

Pacitti Gentil, Samuel; Craizer, Marcos (Advisor). Geometrical aspects of generic polygonal lines: Total curvature and convexity. Rio de Janeiro, 2020. 61p. Dissertação de Mestrado - Departamento de Matemática, Pontifícia Universidade Católica do Rio de Janeiro.

The aim of this work is to study geometrical properties of generic polygonal lines. We begin with some classical results for curves with respect to total curvature, in the discrete case, and discuss results related to polygonal knots. Maxwell graphs are also considered for polygonal lines: We study the relation between the number of components of the graph and the convexity of the polygonal line.

\section{Keywords}

Generic polygonal lines; Total curvature; Maxwell Graph. 


\section{Sumário}

1 Introdução 11

1.1 Nós 11

1.2 Conceitos de Geometria Discreta 14

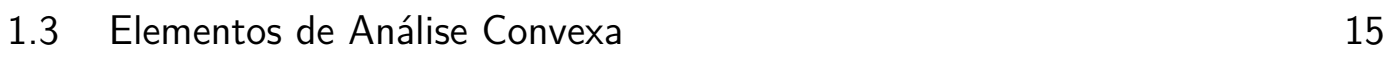

2 O Teorema de Fáry-Milnor $\quad 18$

$\begin{array}{ll}2.1 \text { A curvatura total de uma poligonal } & 18\end{array}$

2.2 O Teorema de Fáry-Milnor: Primeira Demonstração 20

2.3 Segunda Demonstração do Teorema de Fáry-Milnor 22

$\begin{array}{lll}2.4 & \text { O segundo fecho de uma poligonal } & 26\end{array}$

3 Curvas Fechadas e o Grafo de Maxwell 32

$\begin{array}{ll}3.1 & \text { Planos-suporte e fecho convexo } \\ 3.2 & 32\end{array}$

$\begin{array}{lll}3.2 & \text { O Grafo de Maxwell } & 34\end{array}$

3.3 Relações entre a fronteira do fecho convexo e o Grafo de Maxwell 37

3.4 Classificação de pontos do fecho convexo 41

3.5 Relações numéricas 42

3.6 Exemplos interessantes de poligonais 45

4 Alguns Resultados Básicos $\quad 52$

4.1 Geometria Esférica $\quad 52$

4.2 A Propriedade da Interseção Finita para Espaços Compactos 54

4.3 O Teorema da Curva de Jordan 56

4.4 Grafos e Árvores $\quad 57$

4.5 A Característica de Euler $\quad 59$

5 Referências bibliográficas $\quad 60$ 


\section{Lista de figuras}

Figura 1.1 O mesmo nó de trevo, visto por dois ângulos diferentes. 12

Figura 1.2 O mesmo nó de Listing, visto por dois ângulos diferentes. 12

Figura 1.3 O primeiro nó (poligonal) é do mesmo tipo de isotopia que o nó trivial, enquanto que o segundo é do tipo do nó de trevo. 14

$\begin{array}{lll}\text { Figura 2.1 Poligonal usual (A) e poligonal esférica (B). } & 19\end{array}$

Figura 2.2 Para um segmento esférico $\alpha$, dois setores da esfera cujos pontos $x$ são tais que $n_{Q}(x)=1 . \quad 21$

Figura 2.3 Projeção de $P$ em um plano ortogonal a $L$. 22

Figura 2.4 Polígono $X$ inscrito em $P$. 23

$\begin{array}{lll}\text { Figura 2.5 Removendo um vértice da poligonal } P \text {. } & 23\end{array}$

Figura 2.6 Alterando a poligonal $P=\left[v_{1} \ldots v_{n}\right]$. 25

Figura 2.7 Continuando os processo de alteração da poligonal $P$. 25

Figura 2.8 Quadrilátero degenerado inscrito no nó poligonal. 25

Figura 2.9 Duas possibilidades para $y_{2}$. 26

Figura 2.10 F' contém (essencialmente) P, F contém essencialmente P. 28

$\begin{array}{lll}\text { Figura 2.11 Recorte de nós poligonais: três casos. } & 29\end{array}$

Figura 2.12 Tomando um plano $\partial F^{\prime}$ a uma pequena distância de $\partial F . \quad 30$

Figura 3.1 Tipos de planos-suporte: $i / j$ : $i$ vértices no plano, $j$ componentes conexas da interseção

Figura 3.2 Uma poligonal convexa à esquerda, e uma não-convexa à direita 34

Figura 3.3 Em vermelho, planos tritangentes. Em verde, planos bitangentes. $E$, em azul, um plano osculador. Daqui para a frente, todas as figuras usarão o mesmo padrão de cor para os planos tangentes, assim como para seus respectivos vetores normais.

Figura 3.4 Obtenção dos vértices do grafo $G$, junto com a explicitação de alguns planos. Note que o triângulo em vermelho possui dois vértices (não consecutivos) em comum com os outros dois triângulos, e portanto os vértices correspondentes em $G(P)$ serão tais que o em vermelho se conectará aos outros dois.

Figura 3.5 Grafo $G(P)$ com os índices correspondentes para a poligonal $P$ das figuras 3.4 e 3.6. Repare que $G(P)$ possui duas componentes.

Figura 3.6 Ligando os vértices segundo a regra dos dois vértices (não consecutivos) em comum. Diversos ângulos da mesma poligonal $P$ e de seu grafo $G(P)$.

Figura 3.7 Diversas poligonais com seus respectivos grafos de Maxwell. A do canto superior esquerdo é a mesma da figura 3.6.

Figura 3.8 Exemplo de poligonal $P$ com seu grafo de Maxwell $G_{M}(P)$ associado, além de seu fecho convexo $H(P)$ com os painéis com cores distintas: vermelho para 2-painéis, verde para 1-painéis e azul para 0-painéis. Lembramos que o vetor $u \in \mathbb{S}^{2}$ no grafo aponta para o semi-espaço contendo a poligonal.

Figura 3.9 Pré-imagem de um ciclo em um grafo de Maxwell: um vértice isolado ou uma curva poligonal não fechada. 
Figura 3.10 Para três poligonais diferentes, seus fechos convexos e exemplos de tipos de pontos segundo a classificação. As cores representam painéis distintos: vermelho para 2-painéis, verde para 1-painéis e azul para 0-painéis. 42

Figura 3.11 Curva convexa típica quando $k=2$. $C=4$ e $T=0$.

Figura 3.12 Curva convexa típica quando $k=3$. $C=6$ e $T=2$.

Figura 3.13 Nó de trevo usual. $C=0, T=2$ e $\rho=3$. 46

Figura 3.14 Poligonal isotópica ao círculo, porém não-convexa. $C=0$, $T=2$ e $\rho=3$.

Figura 3.15 Poligonal isotópica ao círculo, porém não-convexa. $C=2$, $T=0$ e $\rho=1$.

Figura 3.16 Poligonal isotópica ao círculo, convexa. $C=4$ e $T=0$.

Figura 3.17 Poligonal isotópica ao círculo, não-convexa. $C=2, T=2 \mathrm{e}$ $\rho=2$.

Figura 3.18 Poligonal convexa com grafo de Maxwell mais extenso. $C=8$ e $T=4$.

Figura 3.19 Poligonal convexa cujo grafo de Maxwell contém duas componentes não homeomorfas uma à outra. $C=7$ e $T=3$.

Figura 3.20 Uma poligonal isotópica ao nó de trevo, porém sem planos tritangentes ou osculadores. Importante notar que a "auto-interseção"da aresta do grafo nela mesma é apenas aparente, decorrente da projeção escolhida.

Figura 3.21 Nó de Listing. $C=0, T=8$ e $\rho=6$. Importante notar que a "auto-interseção"da aresta do grafo nela mesma é apenas aparente, decorrente da projeção escolhida. Note ainda que no grafo há dois pares de vértices muito próximos um do outro, porém não iguais. Assim, a condição de a poligonal ser genérica continua sendo preservada. 
I was born not knowing and have had only a little time to change that here and there.

Richard Feynman, . 


\section{1 \\ Introdução}

1.1

Nós

Nesta seção, introduzimos aquilo que passaremos a chamar de nó. Apesar do trabalho se concentrar no estudo de aspectos geométricos de poligonais, em especial de nós poligonais, abordamos nesta seção questões topológicas relevantes para uma distinção importante que faremos sempre que nos referirmos a nós.

Definição 1.1 Uma curva é uma aplicação $\alpha: I \longrightarrow \mathbb{R}^{3}$ contínua de um intervalo $I$ qualquer da reta $\mathbb{R}$ em $\mathbb{R}^{3}$. A curva é dita fechada se $I=[a, b]$ e $\alpha(a)=\alpha(b)$. A curva é dita simples se $\alpha$ é injetiva em $[a, b)$ e em $(a, b]$ (sem auto-interseções, com exceção de possivelmente apenas nos pontos $\{a\}$ e $\{b\})$.

Definição 1.2 Um subconjunto $C \subset \mathbb{R}^{3}$ é dito um nó se $C$ é homeomorfo ao círculo $\mathbb{S}^{1}$. Equivalentemente, $C$ é um nó se é a imagem de uma curva fechada simples $\alpha:[a, b] \longrightarrow \mathbb{R}^{3}$.

Exemplo 1.1.1 O próprio círculo $\mathbb{S}^{1}$ mergulhado em $\mathbb{R}^{3}$, digamos através da curva $\alpha:[0,2 \pi] \longrightarrow \mathbb{R}^{3}$ dada por $\alpha(t)=(\cos t, \sin t, 0)$, é um nó. É o chamado nó trivial.

Exemplo 1.1.2 O nó de trevo é o nó da figura 1.1. Uma parametrização possivel é obtida pela curva $\alpha:[0,2 \pi] \longrightarrow \mathbb{R}^{3}$, dada por

$$
\alpha(t)=(\sin (t)+2 \sin (2 t), \cos (t)-2 \cos (2 t),-\sin (3 t)) .
$$

Exemplo 1.1.3 O nó de Listing é o nó da figura 1.2. Uma parametrização possível é obtida pela curva $\alpha:[0,2 \pi] \longrightarrow \mathbb{R}^{3}$, dada por

$$
\alpha(t)=((2+\cos (2 t)) \cos (3 t),(2+\cos (2 t)) \sin (3 t), \sin (4 t)) .
$$

Os dois exemplos anteriores são casos do que se entende intuitivamente como um nó. Se tivéssemos um modelo físico como uma corda atada em suas duas pontas e configurada como na figura 1.1 (ou como na figura 1.2), não seria possível desatá-la de forma a ficar como um círculo, desde que não nos permitíssemos cortar a corda ao meio. O caso trivial está incluído na 

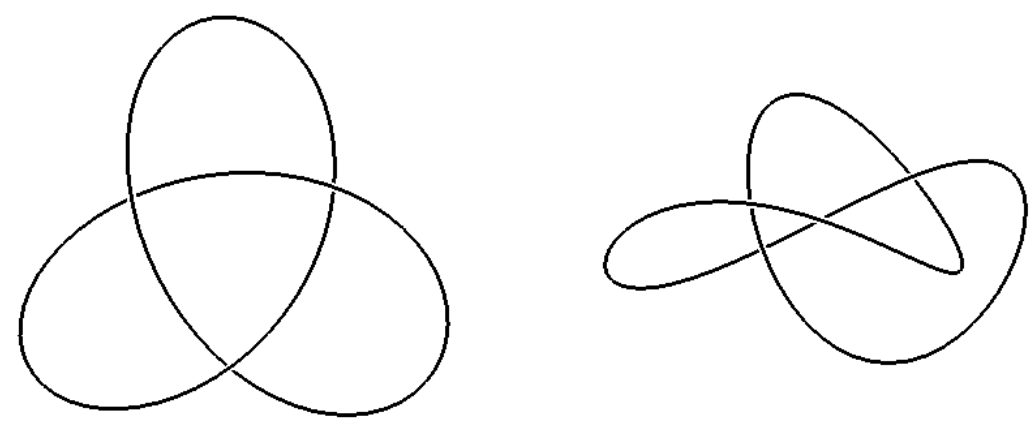

Figura 1.1: O mesmo nó de trevo, visto por dois ângulos diferentes.
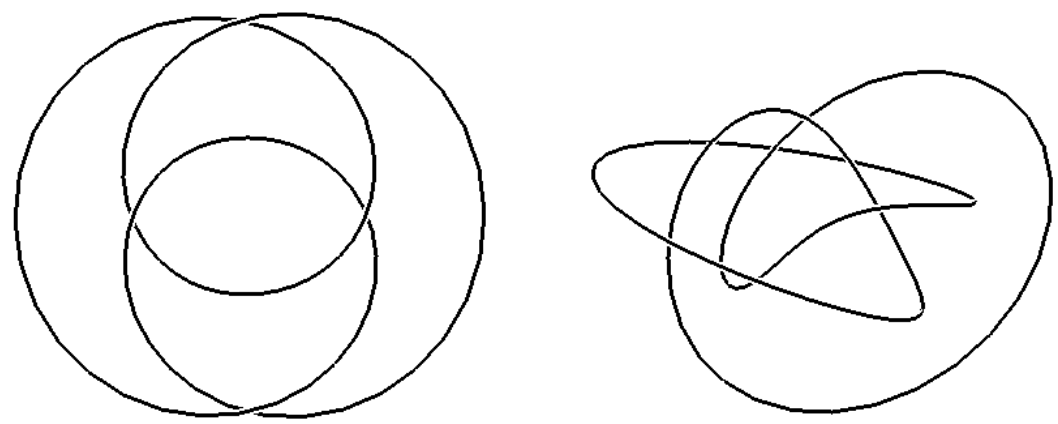

Figura 1.2: O mesmo nó de Listing, visto por dois ângulos diferentes.

definição por uma questão de coerência, mas gostaríamos de excluí-lo de forma a distinguir nós propriamente ditos de uma curva "desatada". Para tal, devemos introduzir uma certa relação de equivalência no conjunto dos nós.

A propriedade de ser um nó está ligada à maneira com a qual a curva $C$ está mergulhada no espaço $\mathbb{R}^{3}$. Tendo um modelo físico da curva, nos perguntamos se é possível deformá-la a uma outra configuração de forma contínua e bijetiva, uma vez que não nos permitimos ações tais como cortar a corda ao meio. Além disso, faz sentido pensar no movimento da corda acompanhado por um movimento de todo o espaço ao redor dela, de forma que essa transformação contínua e bijetiva também se estenda a todo o espaço: isso motiva a seguinte

Definição 1.3 Dois nós $C_{1}$ e $C_{2}$ são equivalentes se existe um homeomorfismo $\phi: \mathbb{R}^{3} \longrightarrow \mathbb{R}^{3}$ do espaço nele mesmo tal que $\phi\left(C_{1}\right)=C_{2}$.

Dessa forma, a afirmação informal de que o círculo, o nó de trevo (figura 1.1) e o nó de Listing (figura 1.2) são diferentes e que não podem ser transformados uns nos outros sem cortá-los pode ser reformulada de modo rigoroso ao dizer que eles pertencem a classes de equivalência distintas segundo a definição acima. 
Evidentemente, a impossibilidade de se transformar cada um dos nós acima no outro não prova que eles não sejam equivalentes. A saída, como em quase todas as questões matemáticas, consiste em achar propriedades dos objetos matemáticos considerados e derivar propriedades invariantes, objetos de outra natureza (digamos, algébrica) etc.

O procedimento clássico é o seguinte: se dois nós $C_{1}$ e $C_{2}$ são equivalentes, segundo a definição anterior, temos que $\phi$ mapeia $\mathbb{R}^{3}-C_{1}$ homeomorficamente em $\mathbb{R}^{3}-C_{2}$. Logo, $\mathbb{R}^{3}-C_{1}$ e $\mathbb{R}^{3}-C_{2}$ possuem grupos fundamentais isomorfos. Portanto, provando-se que estes dois grupos não são isomorfos, prova-se que os dois nós $C_{1}$ e $C_{2}$ não são equivalentes. O grupo fundamental $\pi_{1}\left(\mathbb{R}^{3}-C, p_{0}\right)$ (onde $p_{0}$ é um ponto qualquer em $\mathbb{R}^{3}-C$ ) é chamado do grupo do nó $\mathbf{C}$.

Não nos aprofundaremos nos detalhes deste procedimento. Um resultado interessante, contudo, que citaremos sem prova, é o seguinte

Teorema 1.4 O grupo do nó trivial é cíclico infinito, isto é, $\mathbb{Z}$. O grupo do nó de trevo é dado pela apresentação $\langle x, y: x y x=y x y\rangle$.

Para mais detalhes e uma demonstração deste resultado, indicamos (CF).

Como o primeiro destes grupos é abeliano, e o segundo não, concluímos que o nó de trevo, de fato, não é equivalente ao círculo. Aplicando o mesmo processo a qualquer outro nó, além disso, também fornece um grupo dado por geradores e relações. Diferenciar dois grupos a partir de suas apresentações, contudo, não se revela tarefa usualmente fácil, o que motiva, em Teoria de Nós, a busca por novos invariantes (no caso, dos grupos obtidos). Classicamente, é assim que se conclui a não-equivalência entre nós. Desta maneira, prova-se, entre entre outras coisas, que o nó de Listing também não é equivalente ao nó trivial.

Introduzimos agora uma segunda noção de equivalência entre nós, aproveitando a noção anteriormente concebida do modelo físico do nó. Na noção matemática anterior de equivalência, não se considerava o processo de transformação entre o estágio inicial e o final. Isso motiva a seguinte

Definição 1.5 Uma deformação isotópica de um espaço topológico $X$ é uma família de homeomorfismos $\phi_{t}, 0 \leq t \leq 1$ de $X$ nele mesmo, tal que $\phi_{0} e^{\prime}$ a função identidade $1_{X}: X \longrightarrow X$, e a função $H: I \times X \longrightarrow X$ definida por $H(t, x)=\phi_{t}(x)$, é contínua.

Definição 1.6 Nós $C_{1}$ e $C_{2}$ são ditos do mesmo tipo de isotopia caso exista uma deformação isotópica $\left\{\phi_{t}\right\}$ de $\mathbb{R}^{3}$ tal que $\phi_{1}\left(C_{1}\right)=C_{2}$. 
Esta noção de equivalência é mais forte que a primeira, visto que o homeomorfismo $\phi_{1}$ ao final da isotopia satisfaz à condição da primeira noção de equivalência entre nós.

A partir deste momento, sempre que falarmos de nós, estaremos nos referindo aos que não sejam do mesmo tipo de isotopia que o nó trivial. Assim, o nó de trevo e o nó de Listing constituem, de fato, nós (propriamente ditos).

Identificar visualmente se uma curva como a das figuras anteriores representa de fato um nó não é uma tarefa trivial, embora seja possível deduzir algo em certos casos através de lápis e papel, ou então com um modelo físico de fato. Veja a figura 1.3: no primeiro caso, uma sequência de transformações isotópicas na poligonal revela que a mesma é do mesmo tipo de isotopia que o nó trivial; no segundo caso, recaímos no tipo do nó de trevo.

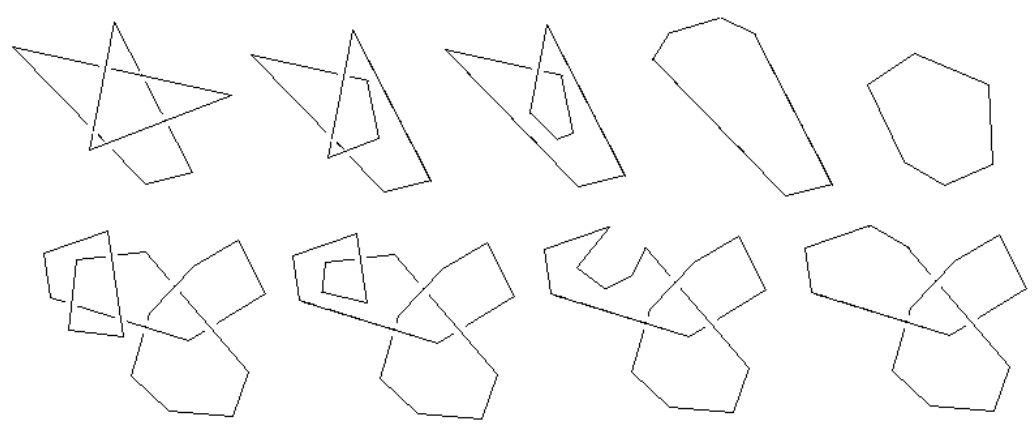

Figura 1.3: O primeiro nó (poligonal) é do mesmo tipo de isotopia que o nó trivial, enquanto que o segundo é do tipo do nó de trevo.

\section{2}

\section{Conceitos de Geometria Discreta}

Nesta pequena seção, introduzimos conceitos básicos de geometria discreta e fixamos certas notações.

O espaço ambiente será o euclidiano $\mathbb{R}^{n}$. Dados dois pontos $v, v^{\prime} \in \mathbb{R}^{n}$, denotamos por $\left[v, v^{\prime}\right]$ o segmento de reta $\left\{(1-t) v+t v^{\prime}: t \in[0,1]\right\}$ (que inclui as extremidades), e por $\left(v, v^{\prime}\right)$ a aresta $\left\{(1-t) v+t v^{\prime}: t \in(0,1)\right\}$ (sem as extremidades). Denotamos a distância euclidiana usual entre esses dois pontos tanto por $\left|\overrightarrow{v v^{\prime}}\right|$ como por $\left|v v^{\prime}\right|$.

Definição 1.7 Dados $n$ pontos $v_{1}, v_{2}, \ldots, v_{n} \in \mathbb{R}^{n}$, definimos a poligonal $P=\left[v_{1}, v_{2}, \ldots, v_{n}\right]$ como sendo a curva obtida através da concatenação dos segmentos de reta $\left[v_{1}, v_{2}\right],\left[v_{2}, v_{3}\right], \ldots,\left[v_{n-1}, v_{n}\right]$ e $\left[v_{n}, v_{1}\right]$ (ou seja, uma curva afim por partes). Uma poligonal é dita simples se é uma curva simples. Um 
nó poligonal é uma poligonal e um nó (propriamente dito). Uma poligonal $P$ é dita genérica se ela não possui 4 vértices coplanares.

\section{3}

\section{Elementos de Análise Convexa}

Introduzimos nesta seção conceitos e resultados básicos em Análise Convexa necessários nos Capítulos seguintes. Para mais detalhes, recomendamos (IS).

Definição 1.8 Um conjunto $X \subset \mathbb{R}^{d}$ é dito convexo se, para quaisquer $x, y \in X$, o segmento $[x, y]=\{(1-t) x+t y ; t \in[0,1]\}$ está contido em $X$.O ponto $(1-t) x+$ ty com $t \in[0,1]$ chama-se a combinação convexa de $x$ e $y$.

Definição 1.9 Mais geralmente, dados $x_{1}, \ldots, x_{n} \in \mathbb{R}^{d}, t_{1}, \ldots, t_{n} \in[0,1]$, tais que $t_{1}+\ldots+t_{n}=1$, o ponto $t_{1} x_{1}+\ldots+t_{n} x_{n}$ é chamado de a combinação convexa dos pontos $x_{1}, \ldots, x_{n}$.

Uma reformulação da noção de convexidade é dada pelo seguinte:

Teorema 1.10 Um conjunto $X$ é convexo se, e somente se, para quaisquer $m \in \mathbb{N}, x_{1}, \ldots, x_{m} \in X, t_{1}, \ldots, t_{m} \in[0,1]$, tais que $t_{1}+\ldots+t_{m}=1$, a combinação convexa $t_{1} x_{1}+\ldots+t_{n} x_{m}$ pertence a $X$.

Prova. Se $X$ contém todas as combinações convexas de seus pontos, então contém em particular todas as combinações convexas de quaisquer dois pontos $(m=2)$. Logo $X$ é convexo, por definição.

Suponha agora que $X$ seja convexo. A prova é por indução sob $m \geq 2$. O caso $m=2$ é a própria condição de convexidade. Suponha, então, o resultado válido para $j=m$ (ou seja, para quaisquer $x_{1}, \ldots, x_{m} \in X$, a combinação convexa $t_{1} x_{1}+\ldots+t_{m} x_{m}$ pertence a $\left.X\right)$.

Para $j=m+1$, sejam $x_{1}, \ldots, x_{m+1} \in X$ e $t_{1}, \ldots, t_{m+1} \in[0,1]$ tais que $t_{1}+\ldots+t_{m+1}=1$, e seja $x=t_{1} x_{1}+\ldots+t_{m+1} x_{m+1}$ a combinação convexa desses elementos.

Se $t_{m+1}=1$, então $t_{1}=\ldots=t_{m}=0$, donde $x=x_{m+1} \in X$.

Se $t_{m+1} \neq 1$, então $t_{1}+\ldots+t_{m}=1-t_{m+1} \geq 0$ e podemos, assim, escrever

$$
\begin{gathered}
x=t_{1} x_{1}+\ldots+t_{m} x_{m}+t_{m+1} x_{m+1} \\
=\left(1-t_{m+1}\right) \frac{t_{1} x_{1}+\ldots+t_{m} x_{m}}{t_{1}+\ldots+t_{m}}+t_{m+1} x_{m+1}
\end{gathered}
$$


Temos que $y:=\frac{t_{1} x_{1}+\ldots+t_{m} x_{m}}{t_{1}+\ldots+t_{m}}=\frac{t_{1}}{t_{1}+\ldots+t_{m}} x_{1}+\ldots+\frac{t_{m}}{t_{1}+\ldots+t_{m}} x_{m}$ é combinação convexa de $x_{1}, \ldots, x_{m}$, pois, $0 \leq \frac{t_{i}}{t_{1}+\ldots+t_{m}} \leq 1$ para cada $i \in\{1, \ldots, m\}$, e além disso a soma de todos esses coeficientes resulta em 1. Pela hipótese de indução para $j=m$, temos que $y \in X$. Dessa forma:

$$
x=\left(1-t_{m+1}\right) y+t_{m+1} x_{m+1}
$$

é combinação convexa de dois pontos de $X$. Como $X$ é convexo, então, por definição, $x \in X$.

Definição 1.11 Seja $X \subset \mathbb{R}^{d}$ um conjunto qualquer. O fecho convexo de $X$, denotado por $H(X)$, é o menor conjunto convexo em $\mathbb{R}^{d}$ que contém $X$ (equivalentemente, é a interseção de todos os conjuntos convexos em $\mathbb{R}^{d}$ que contém $X)$.

Proposição 1.12 Seja $X \subset \mathbb{R}^{d}$ um conjunto qualquer. O fecho convexo de $X$ é o conjunto de todas as combinações convexas de pontos de $X$.

Prova. Denote por $C(X)$ o conjunto de todas as combinações convexas de pontos de $X$. Mostremos que $H(X)=C(X)$.

Como o conjunto $H(X)$ é convexo, então, pelo teorema anterior, $H(X)$ contém todas as combinações convexas de pontos de $H(X)$. Como $X \subset H(X)$, então $H(X)$ contém em particular todas as combinações convexas de pontos de $X$. Ou seja, $C(X) \subset H(X)$.

É evidente que $X \subset C(X)$. Logo, se $C(X)$ for convexo, teremos que $H(X) \subset H(C(X))=C(X)$. Provemos, então, que $C(X)$ é convexo.

Sejam $z, w \in C(X)$. Vale que

$$
\begin{aligned}
& z=r_{1} x_{1}+\ldots+r_{n} x_{n}, \text { onde } \sum_{i=1}^{n} r_{i}=1 \text { e } x_{i} \in X, \forall i \\
& w=s_{1} y_{1}+\ldots+s_{m} y_{m}, \text { onde } \sum_{i=1}^{m} s_{i}=1 \text { e } y_{i} \in X, \forall i
\end{aligned}
$$

Seja agora $t \in[0,1]$. Temos que

$$
\begin{gathered}
v:=(1-t) z+t w \\
=(1-t) \sum_{i=1}^{n} r_{i} x_{i}+t \sum_{i=1}^{m} s_{i} y_{i} \\
=\sum_{i=1}^{n}(1-t) r_{i} x_{i}+\sum_{i=1}^{m} t s_{i} y_{i}
\end{gathered}
$$


Cada coeficiente $(1-t) r_{i}$ e $t s_{i}$ é não-nulo, e, além disso:

$$
\sum_{i=1}^{n}(1-t) r_{i}+\sum_{i=1} t s_{i}=(1-t) \sum_{i=1}^{n} r_{i}+t \sum_{i=1} s_{i}=(1-t)+t=1
$$

o que mostra que o ponto $v$ é combinação convexa dos pontos $x_{1}, \ldots, x_{n}, y_{1}, \ldots, y_{m} \in X$. Logo, $v \in C(X)$. Portanto, $C(X)$ é convexo.

Um resultado do qual nos valeremos mais adiante, enunciado sem demonstração, é o seguinte

Lema 1.13 (Lema de Minkowski) Seja $D \subset \mathbb{R}^{d}$ um conjunto convexo nãovazio e denote seu fecho por $\bar{D}$. Se $x \notin \bar{D}$, então existem $a \in \mathbb{R}^{d}-\{0\}$ e $c \in \mathbb{R}$ tais que

$$
\langle a, x\rangle=c,\langle a, y\rangle>c \forall y \in D \text {. }
$$

Em palavras: existe um plano $H(a, c)=\left\{y \in \mathbb{R}^{d} \mid\langle a, y\rangle=c\right\}$ que contém $x$, mas que não intercepta $D$ (D está inteiramente contido em um dos semi-espaços determinado pelo plano $H(a, c))$.

Para uma prova deste Lema, veja (IS) (págs. 112-113). 


\section{O Teorema de Fáry-Milnor}

Neste capítulo, estabeleceremos para nós poligonais (como definidos no primeiro capítulo) certas propriedades geométricas relacionadas à sua curvatura total e ao seu segundo fecho. Seguiremos aqui as exposições em $(\mathrm{Pa})$ e (CKKS).

\section{1}

\section{A curvatura total de uma poligonal}

Primeiramente, é claro que, dada uma curva $C \subset \mathbb{R}^{n}$, com comprimento $L$, existe uma bola $B \subset \mathbb{R}^{n}$ fechada de raio $L / 2$ tal que $C \subset B$. A proposição seguinte nos fornece uma cota superior mais refinada:

Proposição 2.1 Seja $P \subset \mathbb{R}^{n}$ uma poligonal (fechada) com comprimento $L$. Então, existe uma bola $B \subset \mathbb{R}^{n}$ de raio $L / 4$ tal que $P \subset B$.

Prova. Sejam $x$ e $y$ dois pontos de $P$ que dividam a curva em duas partes com medidas iguais $L / 2$. Seja $z$ o ponto médio do segmento entre $x$ e $y$ (ver figura 2.1.A). Afirmamos que a bola fechada $B(z, L / 4)$ (de centro $z$ e raio $L / 4$ ) contém toda a poligonal $P$. Com efeito, para todo ponto $w \in P$, temos que:

$$
2 \overrightarrow{z w}=\overrightarrow{z w}+\overrightarrow{z w}=(\overrightarrow{z x}+\overrightarrow{x w})+(\overrightarrow{z y}+\overrightarrow{y w})
$$

Como $z$ é o ponto médio do segmento $\overline{x y}$, temos que $\overrightarrow{z x}=-\overrightarrow{z y}$ e, assim:

$$
\begin{gathered}
2 \overrightarrow{z w}=-\overrightarrow{z y}+\overrightarrow{x w}+\overrightarrow{z y}+\overrightarrow{y w}=\overrightarrow{x w}+\overrightarrow{y w} \\
\Longrightarrow|\overrightarrow{z w}|=\frac{1}{2}|\overrightarrow{x w}+\overrightarrow{y w}| \leq \frac{1}{2}(|\overrightarrow{x w}|+|\overrightarrow{y w}|) \leq \frac{1}{2}(L / 2)=\frac{L}{4}
\end{gathered}
$$

Definição 2.2 Uma curva $C \subset \mathbb{R}^{n+1}$ é dita esférica se $C \subset \mathbb{S}^{n}$. Dados dois pontos não antipodais $x, y \in \mathbb{S}^{n}$, o segmento esférico entre $x$ e y é a curva esférica $C$ parametrizada por $\frac{x(1-t)+y t}{|x(1-t)+y t|}, t \in[0,1]$. Uma curva esférica $P$ é chamada de poligonal esférica se é uma curva esférica fechada obtida através da justaposição de segmentos esféricos. Denotamos a distância esférica entre dois pontos $x, y \in \mathbb{S}^{n}$ por $|x y|_{\mathbb{S}^{n}}$ (veja a primeira seção do Capítulo 4 para a definição formal desta distância e a prova da Desigualdade Triangular).

Dado um ponto $z \in \mathbb{S}^{n}$ e um número real $r>0$, uma bola esférica aberta (fechada) B(z,r) é o conjunto de pontos de $\mathbb{S}^{n}$ cuja distância esférica a z é menor (menor ou igual) ar. 


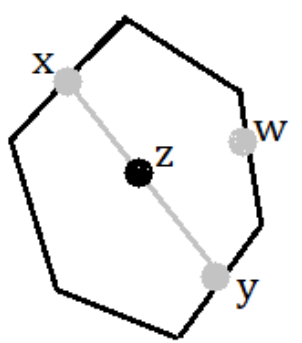

A

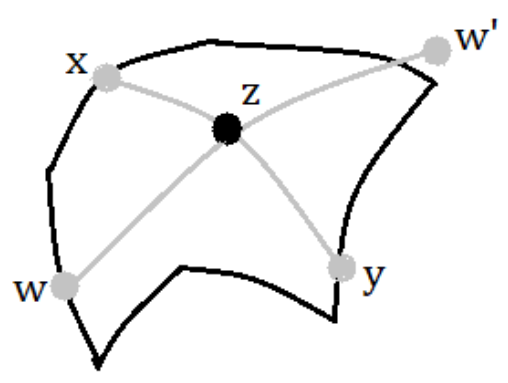

B

Figura 2.1: Poligonal usual (A) e poligonal esférica (B).

A proposição anterior possui um análogo para poligonais esféricas:

Proposição 2.3 Seja $P \subset \mathbb{S}^{n}$ uma poligonal esférica (fechada) com comprimento $L \leq 2 \pi$. Então, existe uma bola esférica $B$ de raio $L / 4$ tal que $P \subset B$.

Prova. Sejam $x$ e $y$ dois pontos de $P$ que dividam a curva em duas partes com medidas iguais $L / 2$. Seja $z$ o ponto médio do segmento esférico que liga $x$ a $y$. Para cada ponto $w \in P$, seja $w^{\prime} \in \mathbb{S}^{n}$ um ponto da esfera tal que $z$ seja o ponto médio do segmento esférico que liga $w$ a $w^{\prime}$. Repare que $w^{\prime}$ pode não estar em $P$. Além disso, pela simetria, vale que $\left|x w^{\prime}\right|=|w y|$ (uma rotação de $\pi$ rad sob o conjunto de pontos $\left.\left\{x, y, w, w^{\prime}\right\}\right)$ troca de posição $x$ com $y$, e $w$ com $w^{\prime}$ - veja a figura 2.1.B). Dessa forma, temos:

$$
\begin{aligned}
|w z|_{\mathbb{S}^{n}}= & \frac{1}{2}\left|w w^{\prime}\right|_{\mathbb{S}^{n}} \leq \frac{1}{2}\left(|w x|_{\mathbb{S}^{n}}+\left|x w^{\prime}\right|_{\mathbb{S}^{n}}\right) \\
& =\frac{1}{2}\left(|w x|_{\mathbb{S}^{n}}+|w y|_{\mathbb{S}^{n}}\right)
\end{aligned}
$$

onde a desigualdade vem da Desigualdade Triangular Esférica (Proposição 4.3).

Como $|w x|_{\mathbb{S}^{n}}+|w y|_{\mathbb{S}^{n}} \leq L / 2$, segue-se que $|w x|_{\mathbb{S}^{n}} \leq L / 4$.

Corolário 2.4 Toda poligonal esférica $P \subset \mathbb{S}^{n}, n \geq 2$, de comprimento $L<2 \pi$ (ou $L=2 \pi$, resp.), está contida em algum hemisfério aberto (ou fechado, resp.) de $\mathbb{S}^{n}$.

Definição 2.5 Dado um triângulo $\Delta(x y z) \subset \mathbb{R}^{n}$, o ângulo exterior $\eta(x y z)$ é definido como

$$
\eta(x y z)=\pi-\angle(x y z)
$$

Dada uma poligonal $P=\left[v_{1} \ldots v_{n}\right] \subset \mathbb{R}^{n}$ simples (sem auto-interseções), definimos a curvatura total $\kappa(P)$ como a soma dos ângulos exteriores:

$$
\kappa(P)=\sum_{i=1}^{n} \eta\left(v_{i-1} v_{i} v_{i+1}\right)
$$


onde os indices $i \pm 1$ são considerados $\bmod n$.

Teorema 2.6 Dada uma poligonal $P=\left[v_{1} \ldots v_{n}\right] \subset \mathbb{R}^{3}, \kappa(P) \geq 2 \pi$. Vale a igualdade se e somente se $P$ é plana e convexa.

Prova. Seja $P=\left[v_{1} \ldots v_{n}\right] \subset \mathbb{R}^{3}$. Para cada vetor $e_{1}=\overrightarrow{v_{1} v_{2}}, \ldots, e_{n-1}=\overrightarrow{v_{n-1} v_{n}}$, $e_{n}=\overrightarrow{v_{n} v_{1}}$, considere um ponto na esfera unitária $x_{i} \in \mathbb{S}^{2}$ tal que $\left(O x_{i}\right)$ seja um vetor unitário com mesma direção e sentido que $e_{i}$. Conectando os pontos $x_{i} \mathrm{e}$ $x_{i+1}$ com o menor caminho (a saber, o segmento esférico), formamos assim uma poligonal esférica $Q=\left[x_{1} \ldots x_{n}\right]$. Por definição, o ângulo exterior $\eta\left(v_{i-1} v_{i} v_{i+1}\right)$ de $P$ é igual ao comprimento da distância $\left|x_{i-1} x_{i}\right|_{\mathbb{S}^{2}}$ na esfera. Logo, $\kappa(P)=|Q|_{\mathbb{S}^{2}}$, o comprimento da poligonal esférica.

Afirmação: $Q$ não está contido em um hemisfério (aberto). Com efeito, do contrário todos os vetores $e_{i}$ estariam apontando para um mesmo semi-espaço e sua soma seria diferente do vetor nulo. Mas isso é impossível, pois, como a poligonal $P$ é fechada, a soma dos vetores $e_{i}$ necessariamente é igual ao vetor nulo.

Por outro lado, pelo corolário anterior, qualquer poligonal esférica com curvatura menor que $2 \pi$ está contida em um hemisfério. Portanto, $|Q|_{\mathbb{S}^{2}} \geq 2 \pi$, provando a primeira parte do teorema.

Para a segunda parte, pelo fato de $\kappa(P)=|Q|_{\mathbb{S}^{2}}$ e pelo corolário anterior, a igualdade $\kappa(P)=2 \pi$ só pode ocorrer quando $P$ está contida em um plano. Para poligonais planas (polígonos) convexas, o resultado segue-se de um cálculo direto a partir dos ângulos interiores.

\section{2}

\section{O Teorema de Fáry-Milnor: Primeira Demonstração}

O resultado principal deste capítulo, cuja versão para curvas suaves fora provada independentemente por Milnor ((Mi)) e Fáry ((Fa)), é o seguinte:

Teorema 2.7 (Teorema de Fáry-Milnor) Para todo nó poligonal $P \subset \mathbb{R}^{3}$, vale que $\kappa(P) \geq 4 \pi$.

Antes da demonstração, algumas notações. Seja $Q \subset \mathbb{S}^{2}$ uma poligonal esférica. Para cada ponto $x \in \mathbb{S}^{2}$, denote por $n_{Q}(x)$ o número de pontos de interseção de $Q$ e do plano $H(x)$ ortogonal a $(O x)$ e que passa pela origem. Os valores de $n_{Q}$ subdividem a esfera em um número finito de regiões $A_{1}, \ldots, A_{k}$ com valor constante $\nu_{i}$ em $A_{i}$. Defina

$$
N_{Q}=\sum_{i=1}^{k} \nu_{i} \cdot \operatorname{área}\left(A_{i}\right)
$$


Lema 2.8 (Fórmula de Crofton) O comprimento $|Q|$ de uma poligonal esférica $Q \subset \mathbb{S}^{2}$ satisfaz à equação

$$
|Q|=\frac{1}{4} N_{Q}
$$

Prova. Como ambos os lados da equação são somas $(|Q|$ é soma dos comprimentos de cada segmento esférico que a compõe), basta provar o lema para segmentos esféricos. Suponha então que $Q \subset \mathbb{S}^{2}$ é um segmento esférico, com $|Q|=\alpha \leq \pi$. Então $n_{Q}(x)=1$ quando $x \in \mathbb{S}^{2}$ está em um grande círculo com normal $(O z)$ para algum $z \in Q$, e $n_{Q}(x)=0$ do contrário. O conjunto $A$ de pontos $x \operatorname{com} n_{Q}(x)=1$ é a união de dois setores da esfera com ângulo $\alpha$ (ver figura 2.2) Assim

$$
N_{Q}=\operatorname{área}(A)=2 \frac{\alpha}{2 \pi} 4 \pi=4 \alpha,
$$

donde $\frac{1}{4} N_{Q}=\alpha=|Q|$.

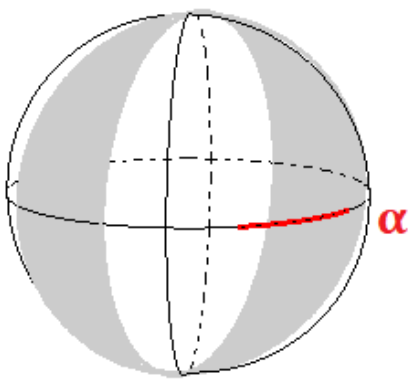

Figura 2.2: Para um segmento esférico $\alpha$, dois setores da esfera cujos pontos $x$ são tais que $n_{Q}(x)=1$.

Precisamos ainda de outro lema:

Lema 2.9 (Lema de Milnor) Seja $P \subset \mathbb{R}^{3}$ uma poligonal simples tal que a função distância a um dado plano L possua exatamente dois pontos críticos. Então, P não é um nó.

Prova. Sejam $x$ e $y$ os pontos de $P$ com a distância mínima e máxima, respectivamente. Logo, $x$ e $y$ dividem $P$ em dois caminhos onde a função distância é monótona crescente. Considere uma projeção de $P$ em um plano genérico perpendicular a $L$, como na figura 2.3. Desfazendo todos os cruzamentos de $x$ a $y$, obtemos uma projeção de uma poligonal isotópica a $P$ sem cruzamentos. Portanto, $P$ não é um nó.

Estamos agora prontos para provar o teorema 2.7:

Prova. (do teorema 2.7) Para um nó poligonal $P \subset \mathbb{R}^{3}$, fixe uma orientação e considere o polígono esférico $Q \subset \mathbb{S}^{2}$ como na demonstração do teorema 2.6. Assim, $\kappa(P)=|Q|$. Para $Q$, considere a subdivisão $A_{1}, \ldots, A_{k}$ correspondente 


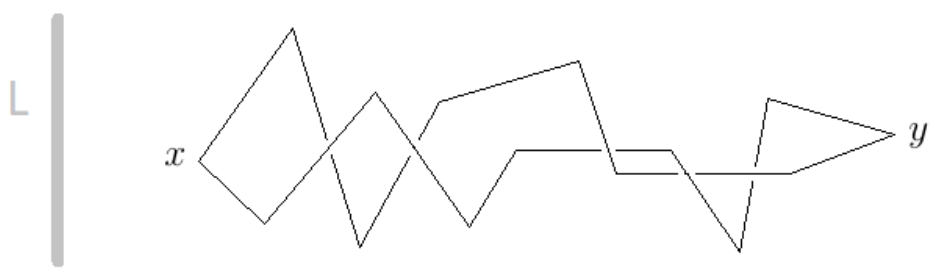

Figura 2.3: Projeção de $P$ em um plano ortogonal a $L$.

da esfera, com os respectivos valores $\nu_{1}, \ldots, \nu_{k}$. Afirmamos que $\nu_{i} \geq 4$ para todo $i$.

Com efeito, suponha que para algum $j \in\{1, \ldots, k\}$ tivéssemos $\nu_{j}<4$. Escolha um ponto $x \in A_{j}$ em posição geral, ou seja, tal que nenhuma aresta (segmento esférico) de $Q$ seja paralela a $H(x)$. Como $\nu_{j}$ é o número de interseções de $Q$ e $H(x)$, é também o número de mudanças de direção das arestas de $P$ com respeito a $H(x)$. Como $P$ é uma poligonal, $\nu_{j}$ necessariamente é par. Logo, $\nu_{j}=2$. Mas, pelo Lema 2.9, isso implica que $P$ não é um nó, contradizendo a hipótese.

Assim, $\nu_{i} \geq 4, \forall i \in\{1, \ldots, k\}$. Portanto, pelo Lema 2.8:

$$
\begin{gathered}
|Q|=\frac{N_{Q}}{4}=\frac{1}{4} \sum_{i=1}^{k} \nu_{i} \cdot \operatorname{area}\left(A_{i}\right) \geq \frac{1}{4} \sum_{i=1}^{k} 4 \cdot \text { área }\left(A_{i}\right) \\
=\sum_{i=1}^{k} \text { área }\left(A_{i}\right)=\text { área }\left(\mathbb{S}^{2}\right)=4 \pi .
\end{gathered}
$$

\section{3}

\section{Segunda Demonstração do Teorema de Fáry-Milnor}

Nesta seção damos uma demonstração mais combinatória do Teorema de Fáry-Milnor.

Definição 2.10 Dadas poligonais $P, X \subset \mathbb{R}^{3}$, dizemos que $X$ está inscrito em $P$ se os vértices de $X$ estão nas arestas de $P$ (ver figura 2.4).

Lema 2.11 Sejam $P, X \subset \mathbb{R}^{3}$ poligonais, de forma que $X$ esteja inscrita em P. Então, $\kappa(X) \leq \kappa(P)$.

Prova. A ideia é adicionar os vértices de $X$ a $P$ e notar que a curvatura dessa "nova"poligonal é a mesma. Em seguida, retiramos os vértices de $P$ que não estão em $X$ e mostrar que esse processo não aumenta a curvatura. 


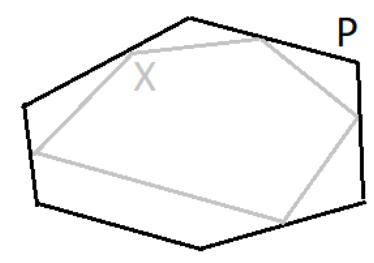

Figura 2.4: Polígono $X$ inscrito em $P$.

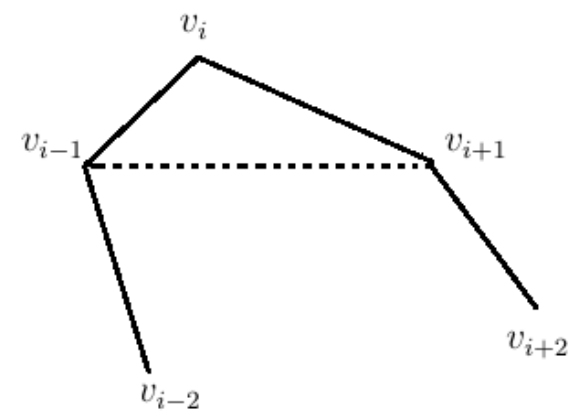

Figura 2.5: Removendo um vértice da poligonal $P$.

Mais explicitamente: seja $P=\left[v_{1}, \ldots, v_{n}\right]$. Remova o vértice $v_{i}$ e substitua as arestas $\left(v_{i-1}, v_{i}\right)$ e $\left(v_{i}, v_{i+1}\right)$ por $\left(v_{i-1}, v_{i+1}\right)$. Denotando a poligonal resultante por $P^{\prime}$ (veja a figura 2.5), mostremos que $\kappa\left(P^{\prime}\right) \leq \kappa(P)$. Com efeito:

$$
\begin{gathered}
\kappa(P)-\kappa\left(P^{\prime}\right)=\left(\pi-\angle\left(v_{i-2} v_{i-1} v_{i}\right)\right)+\left(\pi-\angle\left(v_{i-1} v_{i} v_{i+1}\right)\right) \\
+\left(\pi-\angle\left(v_{i} v_{i+1} v_{i+2}\right)\right)-\left(\pi-\angle\left(v_{i-2} v_{i-1} v_{i+1}\right)\right)-\left(\pi-\angle\left(v_{i-1} v_{i+1} v_{i+2}\right)\right) \\
=-\angle\left(v_{i-2} v_{i-1} v_{i}\right)+\left(\pi-\angle\left(v_{i-1} v_{i} v_{i+1}\right)\right) \\
-\angle\left(v_{i} v_{i+1} v_{i+2}\right)+\angle\left(v_{i-2} v_{i-1} v_{i+1}\right)+\angle\left(v_{i-1} v_{i+1} v_{i+2}\right) \\
=-\angle\left(v_{i-2} v_{i-1} v_{i}\right)+\angle\left(v_{i} v_{i-1} v_{i+1}\right)+\angle\left(v_{i} v_{i+1} v_{i-1}\right) \\
-\angle\left(v_{i} v_{i+1} v_{i+2}\right)+\angle\left(v_{i-2} v_{i-1} v_{i+1}\right)+\angle\left(v_{i-1} v_{i+1} v_{i+2}\right) \\
=\left(\angle\left(v_{i} v_{i-1} v_{i+1}\right)+\angle\left(v_{i-2} v_{i-1} v_{i+1}\right)-\angle\left(v_{i-2} v_{i-1} v_{i}\right)\right) \\
+\left(\angle\left(v_{i} v_{i+1} v_{i-1}\right)+\angle\left(v_{i-1} v_{i+1} v_{i+2}\right)-\angle\left(v_{i} v_{i+1} v_{i+2}\right)\right) \\
\geq 0+0=0
\end{gathered}
$$


onde a desigualdade vem da Desigualdade Triangular Esférica (Proposição 4.3) aplicada a cada termo. Mais precisamente: para o primeiro termo, considere os vetores $\overrightarrow{v_{i-1} v_{i-2}}, \overrightarrow{v_{i-1} v_{i+1}}$ e $\overrightarrow{v_{i-1} v_{i}}$. Normalizando-os e transladando-os de forma que seus pontos de partida estejam na origem, suas extremidades pertencerão à esfera $\mathbb{S}^{2}$, determinando um triângulo esférico. Os lados desse triângulo terão como comprimento justamente as medidas dos ângulos $\angle\left(v_{i} v_{i-1} v_{i+1}\right)$, $\angle\left(v_{i-2} v_{i-1} v_{i+1}\right)$ e $\angle\left(v_{i-2} v_{i-1} v_{i}\right)$, justificando a desigualdade para o primeiro termo. A desigualdade para o segundo termo é análoga.

A ideia para a segunda demonstração do teorema de Fáry-Milnor consiste em tomar um nó poligonal $P$ e considerar uma sequência de poligonais inscritas umas nas outras. Em seguida, mostramos que a última poligonal da sequência (a saber, um quadrilátero degenerado $D=[x y x y]$ ) possui curvatura igual a $4 \pi)$.

Prova. (do teorema 2.7) A prova é por indução sobre o número $n$ de vértices do nó poligonal $P=\left[v_{1} \ldots v_{n}\right] \subset \mathbb{R}^{3}$. Se $n=3, P$ é um triângulo e portanto não é um nó. O teorema vale então por vacuidade.

Pela continuidade da curvatura total de uma poligonal, podemos assumir que os vértices de $P$ estão em posição geral, ou seja, que não há 4 vértices contidos no mesmo plano (poderíamos perturbar levemente a posição de alguns vértices sem que a poligonal deixasse de ser um nó). Uma observação importante é a seguinte: se existe um dado vértice $v_{i}$ tal que o triângulo $\Delta\left(v_{i-1} v_{i} v_{i+1}\right)$ não intersecta nenhuma outra aresta de $P$, podemos então remover $v_{i}$ como na demonstração do lema anterior. Como a nova poligonal ainda é um nó, isotópico ao nó original, obtemos assim o passo indutivo.

Mudamos $P$ da seguinte maneira: começando no vértice $v_{1}$, considere o conjunto de todos os pontos $z \in\left[v_{2}, v_{3}\right], z \neq v_{2}$, tais que $\left(v_{1}, z\right)$ intersecta uma aresta em $P$ (como $P$ é uma poligonal, tal conjunto é finito). Se o conjunto de tais pontos for vazio, removemos o triângulo $\Delta\left(v_{i-1} v_{i} v_{i+1}\right)$ como anteriormente. Do contrário, seja $z_{2}$ o ponto mais próximo de $v_{2}$ com essa propriedade (veja a figura 2.6).

Afirmação: $z_{2} \neq v_{3}$. Com efeito, suponha por absurdo que $z_{2}=v_{3}$. O segmento $\left(v_{1}, v_{3}\right)$ intersectaria então a aresta $\left(v_{j}, v_{j+1}\right)$, para algum $j \in$ $\{4, \ldots, n\}$, donde teríamos quatro pontos, a saber, $v_{1}, v_{3}, v_{j}, v_{j+1}$, em um mesmo plano, contradizendo a genericidade da poligonal $P$.

Denote por $y_{1}$ o ponto de interseção de $\left(v_{1}, z_{2}\right) \operatorname{com} P$ (veja a figura 2.6).

Mova $z_{2}$ levemente em direção a $v_{2}$. Denote por $x_{1}$ o ponto mais próximo de $y_{1}$ na "nova"aresta $\left(v_{1}, z_{2}\right)$. Substitua agora $v_{2}$ de $P$ por $z_{2}$, ou seja, substitua os segmentos $\left[v_{1}, v_{2}\right]$ e $\left[v_{2}, z_{2}\right]$ por $\left[v_{1}, z_{2}\right]$. A poligonal resultante a partir de $P$ continua sendo um nó, isotópico ao anterior, mas possui pontos $x_{1}$ e $y_{1}$ muito 

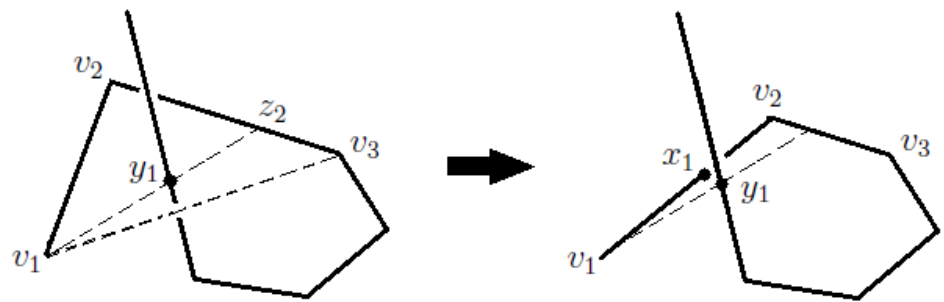

Figura 2.6: Alterando a poligonal $P=\left[v_{1} \ldots v_{n}\right]$.

próximos um do outro.

Ponha $v_{2}:=z_{2}$. Repita o procedimento para o (novo) vértice $v_{2}$ : Novamente, substitua o vértice $v_{3}$ por $z_{3} \in\left(v_{3}, v_{4}\right)$, obtendo dois pontos $x_{2} \in\left(v_{2}, v_{3}\right)$ e $y_{2} \in P$ muito próximos um do outro (veja figura 2.7). Há, então, duas possibilidades para $y_{2}$ relativamente aos pontos $x_{1}, y_{1} \in P$.
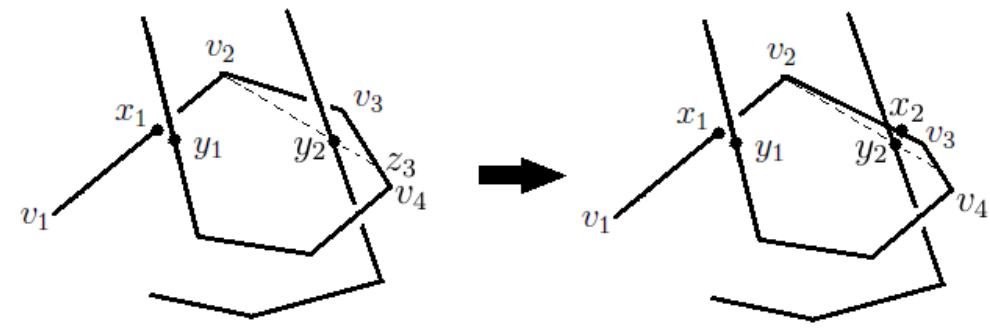

Figura 2.7: Continuando os processo de alteração da poligonal $P$.

Se $y_{2}$ está no arco $\left[y_{1} \ldots x_{1}\right]$ da poligonal, então o quadrilátero inscrito $\left[x_{1} x_{2} y_{1} y_{2}\right]$ está muito próximo de um quadrilátero degenerado da forma $D=$ [abab] (veja figura 2.8), e portanto pode ser tão fechado quanto se deseje.
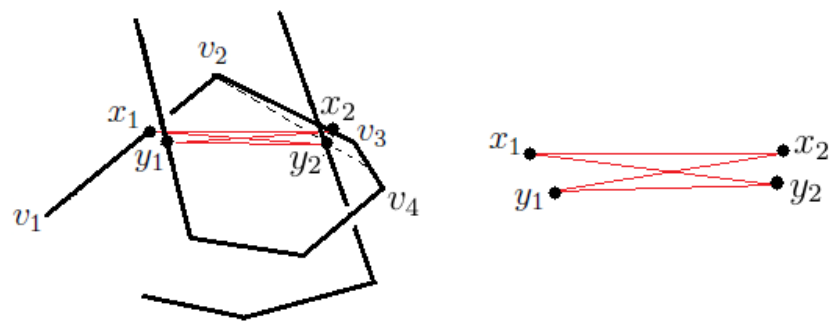

Figura 2.8: Quadrilátero degenerado inscrito no nó poligonal.

Se, por outro lado, $y_{2}$ está no arco $\left[x_{1} \ldots y_{1}\right]$ da poligonal, então o arco $\left[x_{2} y_{2}\right]$ está contido inteiramente no arco $\left[x_{1} \ldots y_{1}\right]$, o que significa que no espaço de parâmetros da poligonal (ver figura 2.9) os segmentos $\left[x_{1}, y_{1}\right]$ e $\left[x_{2}, y_{2}\right]$ não se intersectam. Repita o procedimento até que dois tais segmentos se intersectem (recaindo então no caso anterior). Isso necessariamente acontecerá pois, por 
construção, os pontos $x_{i}$ e $y_{i}$ não podem pertencer a arestas adjacentes. Isso completa o passo indutivo e prova, assim, o teorema.

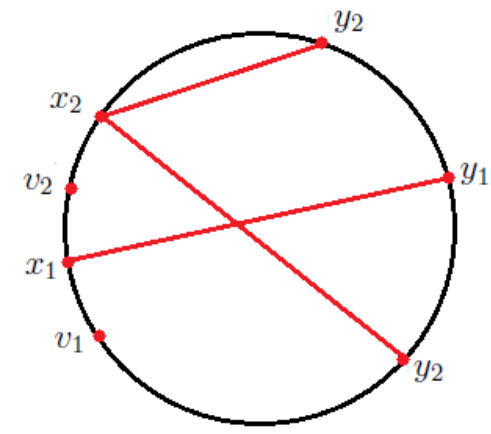

Figura 2.9: Duas possibilidades para $y_{2}$.

\section{4}

\section{O segundo fecho de uma poligonal}

Nesta seção, abordamos uma generalização do Lema de Milnor (lema 2.9), que usa a noção de segundo fecho convexo de uma poligonal. Antes disso, uma proposição:

Proposição 2.12 Dado um conjunto conexo $X \subset \mathbb{R}^{d}$, seja $H(X)$ seu fecho convexo. Então, todo plano $\Pi$ que intersecta um ponto de $H(X)$ necessariamente intersecta algum ponto de $X$.

Prova. Seja $y \in \Pi \cap H(X)$. Se $y \in X$, não há o que demonstrar. Se $y \in H(X)-X$, temos que $y$ é combinação convexa de pontos $x_{1}, x_{2}, \ldots, x_{k} \in X$. Se ao menos um de tais pontos estiver em $\Pi$, segue o resultado. Caso contrário, então afirmamos que cada um dos dois semi-espaços determinados por $\Pi$ contém ao menos um ponto dos $x_{i}$ 's.

Com efeito, se todos os $x_{i}$ 's estivessem em apenas um lado de $\Pi$, então qualquer combinação convexa de tais pontos (como y) estaria no mesmo lado de $\Pi$. Em particular, $y \notin \Pi$. Contradição.

Sem perda de generalidade, então, podemos assumir que $x_{1}$ e $x_{2}$ estão em lados opostos de $\Pi$. Seja então $d_{\Pi}: X \longrightarrow \mathbb{R}$ a função distância ao plano П. Mais explicitamente: se $\eta$ é o vetor normal ao plano $\Pi$ que aponta para o semi-espaço contendo $x_{1}$, então $d_{\Pi}$ é dado por $d_{\Pi}(x)=\langle x-y, \eta\rangle$.

Segue-se que $d_{\Pi}\left(x_{1}\right)>0$ e que $d_{\Pi}\left(x_{2}\right)<0$. Como $X$ é um subconjunto conexo de $\mathbb{R}^{d}$ e $d_{\Pi}$ é uma função contínua, então, pelo Teorema do Valor Intermediário, existe $x_{0} \in X$ tal que $d_{\Pi}\left(x_{0}\right)=0$, ou seja, $x_{0} \in \Pi$. 
Definição 2.13 Seja $P \subset \mathbb{R}^{3}$ uma poligonal simples. Um plano $\Pi$ é dito genérico se não contém vértices de $P$.

Proposição 2.14 Seja $P$ uma poligonal simples. Todo plano genérico П intersecta $P$ um número par de vezes.

Prova. Se a interseção entre a poligonal e o plano é vazia, segue-se o resultado trivialmente.

Suponha então que a interseção é não-vazia. A partir de um vértice $v \in P$ que não esteja em $\Pi$, percorremos a poligonal até voltarmos a $v$. A hipótese de o plano ser genérico garante que a cada ponto de interseção entre $P$ e $\Pi$, atravessamos de fato o plano $\Pi$. A hipótese de a poligonal ser simples, por outro lado, assegura que os pontos obtidos nesse processo são sempre distintos. Portanto, após um número ímpar de pontos de interseção, estaremos no lado de $\Pi$ oposto ao do vértice $v$, enquanto que após um número par de pontos interseção, estaremos no mesmo lado de $\Pi$ contendo $v$. Segue o resultado.

Corolário 2.15 Se P é uma poligonal simples (isto é, sem auto-interseções) em $\mathbb{R}^{d}$, então o fecho convexo $H(P)$ consiste nos pontos q pelos quais qualquer plano genérico $\Pi$ que passa por $q$ (ou seja, $q \in \Pi$ ) intersecta $P$ pelo menos duas vezes.

Prova. Seja $q \in H(P)$ e $\Pi$ um plano genérico que passa por $q$. Pela Proposição 2.12, $P \cap \Pi$ é não-vazia. Pela Proposição 2.14, o número de pontos de interseção de $\Pi$ com $P$ é par. Portanto, $\Pi$ intersecta $P$ em pelo menos dois pontos.

Agora, mostremos que se $q \in \mathbb{R}^{3}$ não pertence a $H(P)$, então existe um plano $\Pi$ que passa por $q$ mas não intersecta $H(P)$.

Como $H(P)$ é um conjunto convexo não-vazio e $q \notin \overline{H(P)}=H(P)$ (pois $H(P)$ é fechado), temos, pelo Lema de Minkowski (Lema 1.13), que existe um plano $\Pi$ que contém $q$ mas cuja interseção com $H(P)$ é vazia.

O fecho convexo captura a ideia intuitiva do conjunto de pontos "delimitado"pelo conjunto inicial. No caso de poligonais, faz sentido considerar o conjunto de pontos do fecho convexo que estão, de certa forma, "mais cercados"pela poligonal. Isso motiva a seguinte

Definição 2.16 Definimos o segundo fecho $S H(P)$ da poligonal $P$ como o conjunto dos pontos $x \in H(P)$ tal que todo plano genérico $\Pi$ que contém $x$ intersecta $P$ em pelo menos 4 pontos.

Lema 2.17 Para uma poligonal $P$, cada componente conexa de $S H(P)$ é convexa. Além disso, $S H(P) \subset H(P)$. 
Prova. Seja $C$ uma componente conexa de $S H(P)$. Se $q$ é um ponto do seu fecho convexo (ou seja, de $H(C)$ ), então, pela Proposição 2.12, qualquer plano $\Pi$ que passe por $q$ também interceptará $C$ em algum ponto $q^{\prime}$. Como $\Pi$ é um plano que passa por $q^{\prime} \in C \subset S H(P)$, temos que $\Pi$ intercepta $P$ pelo menos 4 vezes. Então, por definição, $q \in S H(P)$.

A segunda parte da afirmação segue-se da definição de $S H(P)$ junto com o Corolário anterior.

O segundo fecho $S H(P)$ pode ser vazio, como por exemplo quando $P$ é um triângulo. Para nós poligonais, por outro lado, temos que o segundo fecho é sempre não-vazio. Para a demonstração, precisamos de alguns resultados e definições.

Lema 2.18 Dada uma poligonal $P$ e pontos $x, y \in P$, considere uma poligonal $P^{\prime}$ obtida substituindo a porção de $P$ entre $x$ e y por um segmento $(x, y)$. Então, $S H\left(P^{\prime}\right) \subset S H(P)$.

Prova. Se um plano genérico $\Pi$ passa por um ponto $q \in S H\left(P^{\prime}\right)$ e dessa forma intersecta $P^{\prime}$ pelo menos quatro vezes, então pelo menos três dessas interseções serão em $P^{\prime}-(x, y) \subset P$. Como o número de interseções de $\Pi$ com $P$ tem que ser par, precisa ser ao menos 4 . Logo, $q \in S H(P)$.

Definição 2.19 Seja $F \subset \mathbb{R}^{3}$ um semi-espaço fechado determinado por um plano $\Pi$. Dizemos que F contém essencialmente $P$ se ou contém $P$, ou se intersecta $P$ em exatamente dois pontos $x, y$ de forma que o arco de $P$ de $x$ a $y$ unido ao segmento $[x, y]$ forme um nó trivial (ver figura 2.10).

Neste caso, defina o recorte de $P$ por $F$ como $\operatorname{clip}_{F}(P)=(F \cap P) \cup$ $(x, y)$, a poligonal isotópica a $P$ contida em $F$.

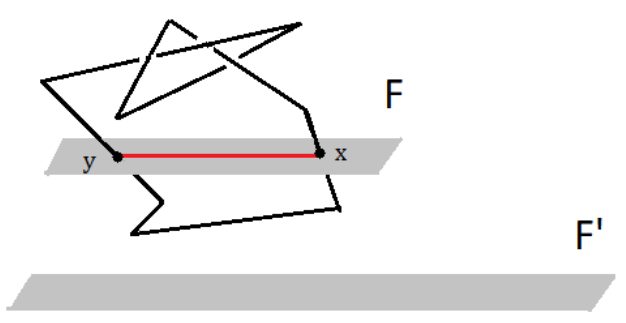

Figura 2.10: F' contém (essencialmente) P, F contém essencialmente P.

O lema a seguir mostra que planos que contêm essencialmente uma dada poligonal também contêm essencialmente qualquer recorte da mesma: 
Lema 2.20 Sejam $F$ e $G$ dois semi-espaços que contém essencialmente o nó poligonal $P$ (denote os respectivos planos por $\partial F$ e $\partial G$ ). Então, $G$ contém essencialmente $\operatorname{clip}_{F}(P)$.

Prova. Precisamos mostrar que $G$ ou contém (propriamente dito) $\operatorname{clip}_{F}(P)$, ou que o arco simples deste novo nó poligonal e que se encontra fora de $G$ não configura um nó não-trivial.

Se $G$ contém $P$, então, pela convexidade de $G$, temos $H(P) \subset G$. Além disso, $\operatorname{clip}_{F}(P) \subset H(P)$ pois cada ponto da aresta $(x, y)$ introduzida é combinação convexa dos pontos $x, y$ do recorte. Assim, $\operatorname{clip}_{F}(P) \subset G$.

Do contrário, sejam $x, y$ os pontos de $P \cap \partial F$ e $x^{\prime}, y^{\prime}$ os pontos de $P \cap \partial G$. Considere o arco de $P$ fora de $G$, e conte quantas de suas pontas $x^{\prime}, y^{\prime}$ estão fora de $F$. Os três diferentes casos aparecem na figura 2.11.

Se $x^{\prime}, y^{\prime} \notin F$, então $\operatorname{clip}_{F}(P) \in G$. Se $x^{\prime}, y^{\prime} \in F$, então o arco de $x^{\prime}$ a $y^{\prime}$ não forma um nó, assim como o seu subarco de $x$ a $y$. O recorte de $P$ por $G$ substitui este subarco pelo segmento isotópico ao mesmo em $\partial F$ (a saber, $[x, y])$, logo o arco de $\operatorname{clip}_{F}(P)$ de $x^{\prime}$ a $y^{\prime}$, fora de $G$, não forma um nó. Em ambos os casos, $G$ contém essencialmente $\operatorname{clip}_{F}(P)$, por definição.

No terceiro caso, $x^{\prime} \notin F$ e $y^{\prime} \in F$. Isso implica que os dois semi-espaços necessariamente dividem o espaço em quatro quadrantes, com $P$ dando uma volta em torno da linha de interseção entre $\partial F$ e $\partial G$. O nó poligonal $P$ é uma soma de quatro arcos, um em cada quadrante. Como tanto $F$ como $G$ contém essencialmente $P$, tanto a soma dos dois arcos fora de $F$ como a soma dos dois arcos fora de $G$ não formam nós. Assim, o nó ocorre de fato em $F \cap G$. Repare ainda que o arco de $\operatorname{clip}_{F}(P)$ fora de $G$ consiste em um arco original em um quadrante (que não formava nó), mais um segmento reto em $\partial F$. Logo este arco não forma um nó e, portanto, $G$ contém essencialmente $\operatorname{clip}_{F}(P)$ também neste caso.
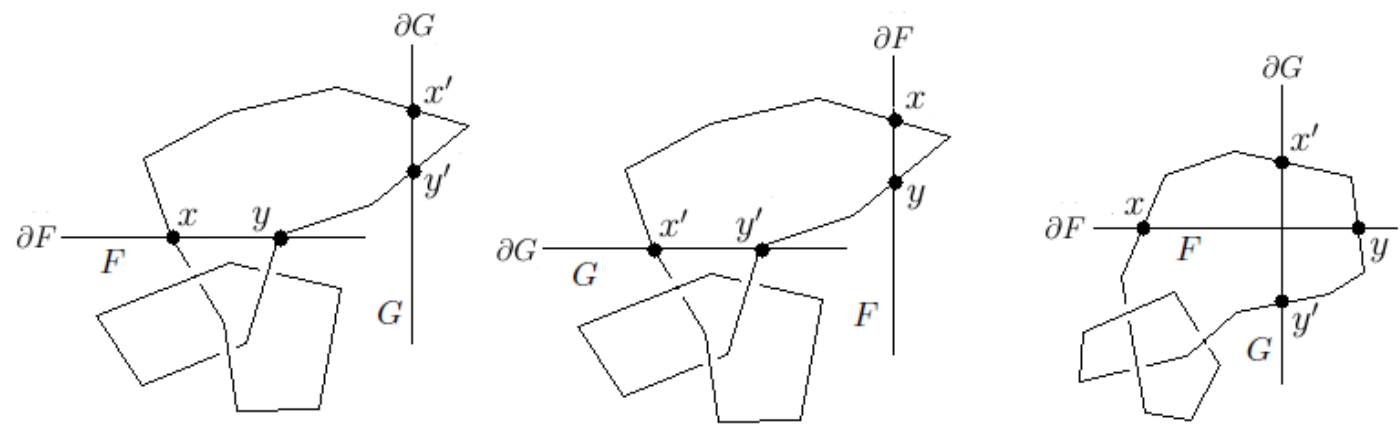

Figura 2.11: Recorte de nós poligonais: três casos. 
Definição 2.21 Dizemos que um nó poligonal $P$ é geometricamente composto se existe um plano $\Pi$ (intersectando $P$ em dois pontos $x$ e y) que decompõe $P$ em dois arcos que formam (cada um, ao ser unido ao segmento $[x, y]$ ) um nó não-trivial. Do contrário, dizemos que P é geometricamente primo.

Teorema 2.22 Para todo nó poligonal $P \subset \mathbb{R}^{3}$, o segundo fecho $S H(P)$ é não-vazio.

Prova. Podemos assumir que $P$ é geometricamente primo. Se não fosse, bastaria substituir $P$ por $P^{\prime}$, uma de suas duas partes que formam um nó. Pelo Lema 2.18, $S H\left(P^{\prime}\right) \subset S H(P)$. Reduzimos então a questão para um polígono com menos arestas.

Seja $\mathcal{F}=\mathcal{F}(P)$ o conjunto de todos os semi-espaços fechados que contém essencialmente $P$, e ponha $Z:=\cap_{F \in \mathcal{F}} F$ como a interseção de todos os tais semi-espaços. Afirmamos que $Z \subset S H(P)$, e que além disso $Z$ é um conjunto convexo não-vazio.

Para a primeira parte da afirmação, seja $z \in Z$ e $\Pi$ um plano genérico que passa por $z$. Suponha, por absurdo, que $\Pi$ intersecta $P$ somente em dois pontos. Como $P$ é geometricamente primo, os arcos em ambos os lados do plano não podem formar nó. Assim, para um arco que não forma nó, seja $F$ o semi-espaço do lado oposto (assim, $\Pi=\partial F$ ). Seja agora $F^{\prime}$ o semi-espaço contido em $F$ de forma que $\partial F^{\prime}$ esteja a uma pequena distância $\varepsilon>0$ de $\partial F$ (ver figura 2.12). Temos que $F^{\prime}$ contém essencialmente $P$, mas $z \notin F^{\prime}$, o que contradiz o fato de $z \in Z$. Portanto, o plano genérico $\Pi=\partial F$ intersecta $P$ mais de duas vezes. Como o plano é genérico e portanto o número de interseções é par, concluímos que este número é de pelo menos 4. Logo, $z \in S H(P)$.

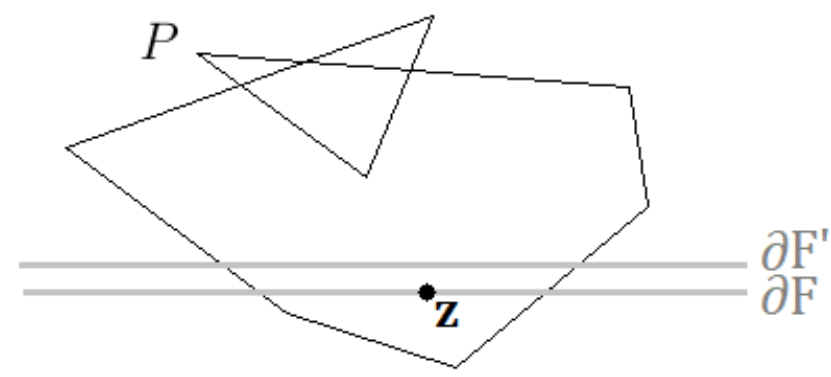

Figura 2.12: Tomando um plano $\partial F^{\prime}$ a uma pequena distância de $\partial F$.

Para a segunda parte da afirmação, repare que, como planos genéricos que passam por $Z$ intersectam $P$ ao menos 4 vezes, então $Z \subset S H(P) \subset H(P)$, 
e assim podemos escrever

$$
Z=\cap_{F \in \mathcal{F}}(F \cap H(P))
$$

Dessa forma, vemos que $Z$ é uma interseção infinita de espaços compactos. Para mostrar que $Z \neq \emptyset$, basta provar que qualquer interseção finita é nãovazia. De fato, pela Propriedade da Interseção Finita (Teorema 4.8) para o espaço compacto $H(P)$, isso implicará que a interseção infinita é não-vazia.

Suponha então que $F_{1}, F_{2}, \ldots, F_{n}$ sejam semi-espaços contendo essencialmente o nó poligonal $P$. Recortando $P$ sucessivamente por estes semi-espaços, definimos $P_{0}=P$ e $P_{i}=\operatorname{clip}_{F_{i}}\left(P_{i-1}\right)$. Como $P$ está essencialmente contido em cada $F_{j}$, isso também vale para cada um dos $P_{j}$, usando o lema 2.20. Portanto, $P_{n}$, um nó poligonal isotópico a $P$, está contido em

$$
\cap_{i=1}^{n} F_{i} \cap H(P),
$$

mostrando que este conjunto é não-vazio.

O Teorema anterior generaliza o Lema de Milnor (Lema 2.9) da seguinte maneira: o Lema de Milnor diz que se existe uma família de planos paralelos que passam por todos os pontos de $\mathbb{R}^{3}$ e que intersectam cada um a poligonal $P$ no máximo duas vezes, então $P$ não é um nó. O Teorema que acabamos de provar (ou melhor, sua contra-positiva, a saber, "Se o segundo fecho $S H(P)$ for vazio, então o $P$ não é um nó") afirma o mesmo, porém sem a hipótese de os planos serem paralelos. 


\section{3}

\section{Curvas Fechadas e o Grafo de Maxwell}

Neste capítulo, apresentamos uma discretização de um problema relacionado a curvas suaves, como apresentado em $(\mathrm{Fu})$. Neste artigo, a autora impõe às curvas certas condições, chamadas de condições de genericidade (genericity conditions), o que permite construir o chamado Grafo de Maxwell da curva, obtendo resultados interessantes.

No presente trabalho, para obter resultados correspondentes para o caso discreto, exigimos que as poligonais não possuam 4 de seus vértices em um mesmo plano. Isso possibilitou o estabelecimento de um algoritmo para a construção do grafo de Maxwell no caso discreto, e a subsequente implementação (em linguagem $\mathrm{C}++$ ) de um programa que calcula este grafo para uma dada poligonal e permite a sua visualização. As imagens que aparecem para ilustrar os diversos grafos de Maxwell associados às poligonais utilizadas foram geradas através deste programa.

Ao final, retomamos brevemente a discussão para nós poligonais, sob o ponto de vista dos grafos de Maxwell associados aos mesmos.

\section{1}

\section{Planos-suporte e fecho convexo}

Definição 3.1 Dada uma poligonal simples $P$ (ou seja, fechada e sem autointerseções) e genérica (tal que não há 4 de seus vértices em um mesmo plano), um plano-suporte (global) é um plano afim $\Pi$ tal que sua interseção com a poligonal é não-vazia e, além disso, de forma que a poligonal esteja inteiramente contida em um dos semi-espaços fechados determinados por $\Pi$.

Segue-se da definição que se um plano-suporte $\Pi$ intercepta uma certa aresta da poligonal, então necessariamente a contém e portanto contém também os dois vértices adjacentes. Como a poligonal é genérica, o número máximo de vértices que um plano pode interceptar é 3. Além disso, alguns destes vértices podem ser seguidos uns dos outros na poligonal (isto é, $\left\{v_{i}, v_{i+1}\right\} \subset P \cap \Pi$ ou $\left\{v_{i}, v_{i+1}, v_{i+2}\right\} \subset P \cap \Pi$, para algum $i \in\{1, \ldots, n\}$, onde $n$ é o número de pontos da poligonal e os índices são tomados $\bmod n$ ). Essas observações nos permitem classificar os planos-suporte em 6 tipos $i / j$, ilustrados na figura 3.1: $i$ representa o número de vértices na interseção do plano com a poligonal, $j$, o número de componentes conexas da interseção.

Estamos interessados nos planos-suporte que interceptam a poligonal em três pontos. Um tal plano-suporte será dito então tritangente caso seja do 
tipo $3 / 3$, bitangente caso seja do tipo $3 / 2$ ou osculador caso seja do tipo $3 / 1$.

Cada plano tritangente $\Pi$ será denotado por $\Pi(i, j, k)$, onde $i<j<k$ são os índices dos vértices contidos no plano. Denote ainda por $\Delta(i, j, k)$ o triângulo determinado por esses mesmos três vértices. Note que pela condição de genericidade da poligonal, não pode haver três vértices colineares.

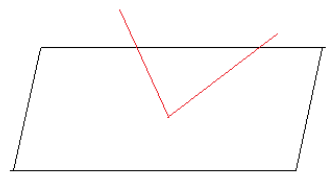

$1 / 1$

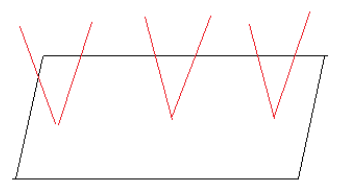

$3 / 3$

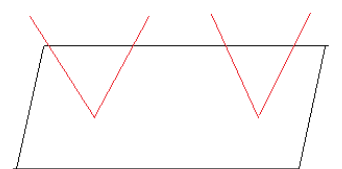

$2 / 2$

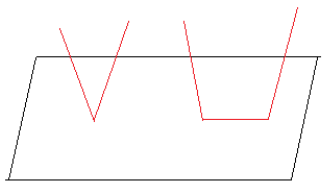

$3 / 2$

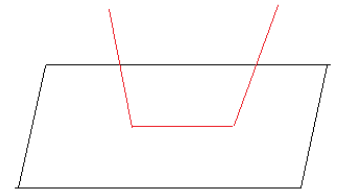

$2 / 1$

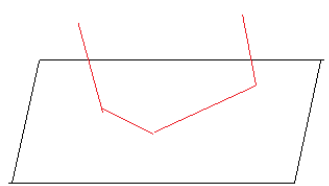

$3 / 1$

Figura 3.1: Tipos de planos-suporte: $i / j: i$ vértices no plano, $j$ componentes conexas da interseção

Definição 3.2 Dada uma poligonal $P \in \mathbb{R}^{3}$, seja $H(P)$ o seu fecho convexo. Denotamos a fronteira desse conjunto por $\partial H(P)$. Chamamos de parte externa da poligonal $P$ o conjunto $P \cap \partial H(P)$ e o denotamos por Ext $(P)$.

Observação 3.1.1 Dada uma poligonal genérica simples $P, \partial H(P)$ é igual à união de todos os triângulos $\Delta(i, j, k)$ que estão contidos em planos-suporte $\Pi(i, j, k)$.

Definição 3.3 Dada uma poligonal $P \in \mathbb{R}^{3}$, dizemos que ela é convexa se $P \subset \partial H(P)$, ou equivalentemente, se $P=\operatorname{Ext}(P)$.

A figura 3.2 ilustra duas poligonais com seus respectivos fechos convexos. 

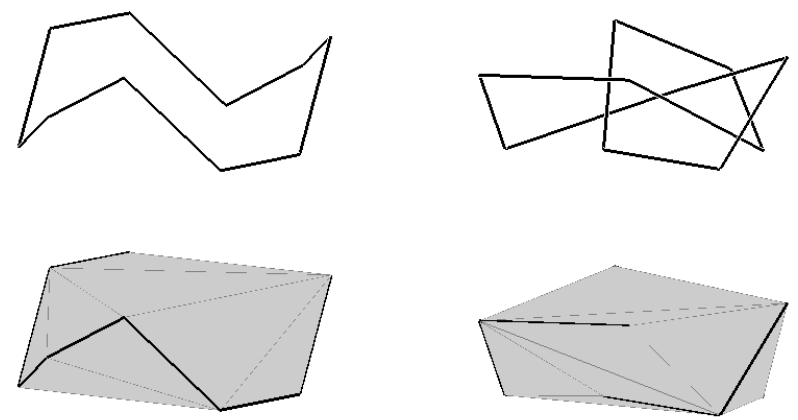

Figura 3.2: Uma poligonal convexa à esquerda, e uma não-convexa à direita
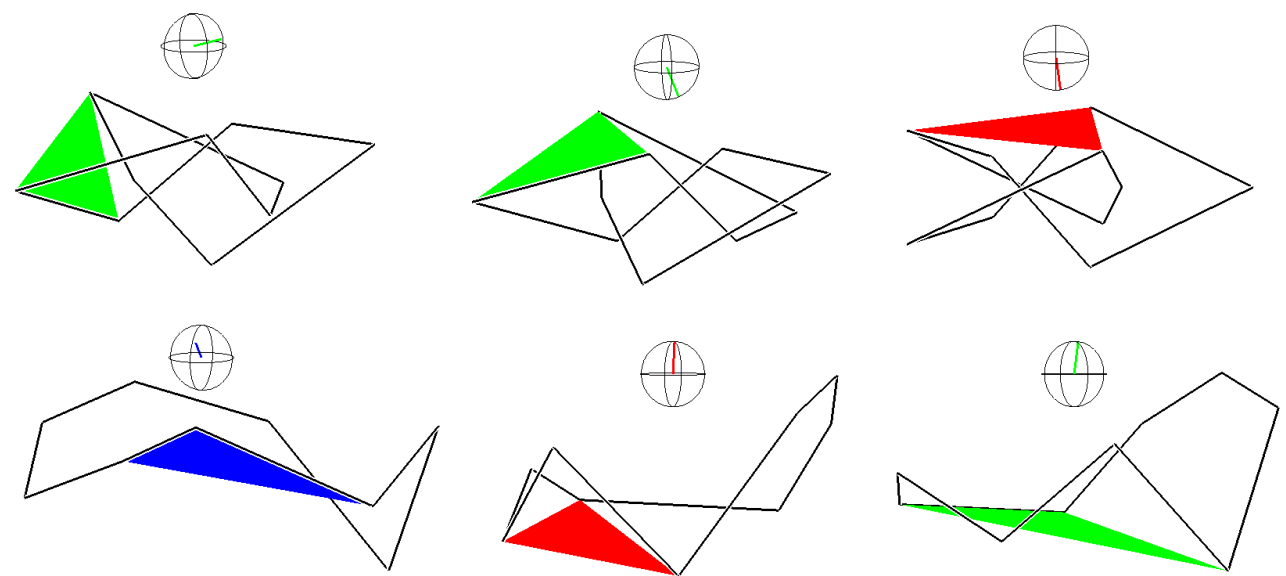

Figura 3.3: Em vermelho, planos tritangentes. Em verde, planos bitangentes. E, em azul, um plano osculador. Daqui para a frente, todas as figuras usarão o mesmo padrão de cor para os planos tangentes, assim como para seus respectivos vetores normais.

\section{2}

\section{O Grafo de Maxwell}

Antes de vir a definir o Grafo de Maxwell, definimos um grafo preliminar $G$.

Dada uma poligonal $P$, construa o grafo $G(P)$ da seguinte forma: para cada plano-suporte $\Pi(i, j, k)$, seja $n(i, j, k)$ o vetor unitário normal ao plano de forma que ele aponte para o semi-espaço que contém a poligonal. A figura 3.3 ilustra, para certas poligonais, alguns triângulos representando seus respectivos planos-suporte que os contém, junto com o vetor normal correspondente. As extremidades de todos vetores serão os vértices do grafo $G(P)$.

Uma convenção: dada uma poligonal, com $n$ vértices, dizemos que dois números inteiros distintos $i<j$ são consecutivos se $j=i+1$ ou se $i=1 \mathrm{e}$ 

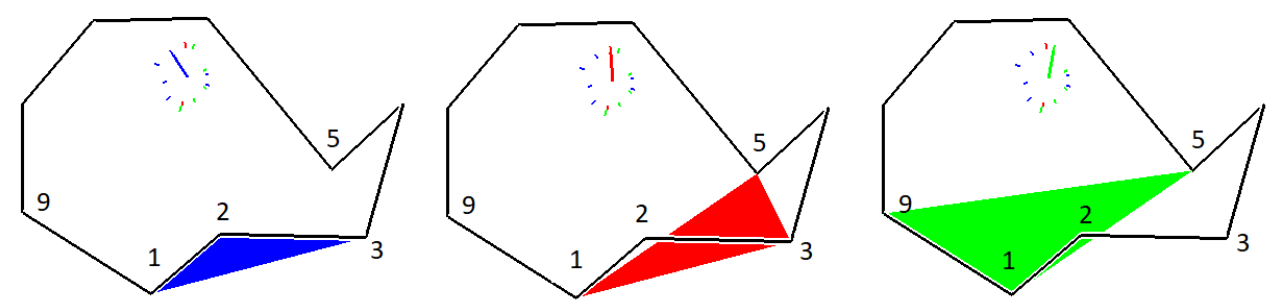

Figura 3.4: Obtenção dos vértices do grafo $G$, junto com a explicitação de alguns planos. Note que o triângulo em vermelho possui dois vértices (não consecutivos) em comum com os outros dois triângulos, e portanto os vértices correspondentes em $G(P)$ serão tais que o em vermelho se conectará aos outros dois.

$j=n$.

As arestas de $G(P)$ serão obtidas então a partir da seguinte regra (ver figura 3.5):

- se $n(i, j, k)$ é normal a um plano tritangente, conecte-o através de um segmento esférico a qualquer $n(a, b, c)$ com exatamente dois índices iguais (haverá exatamente três n's);

- se $n(i, j, k)$ é normal a um plano bitangente, conecte-o através de um segmento esférico a qualquer $n(a, b, c)$ com exatamente dois índices iguais que não sejam consecutivos (haverá exatamente dois n's);

- se $n(i, j, k)$ é normal a um plano osculador, conecte-o através de um segmento esférico ao único $n(a, b, c)$ com exatamente dois índices iguais que não sejam consecutivos.
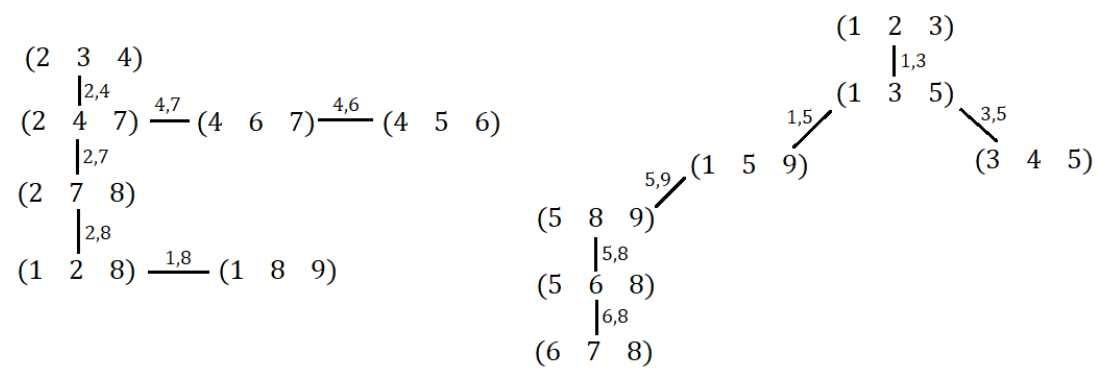

Figura 3.5: Grafo $G(P)$ com os índices correspondentes para a poligonal $P$ das figuras 3.4 e 3.6. Repare que $G(P)$ possui duas componentes.

A figura 3.6 ilustra a obtenção das arestas do grafo.

As regras anteriores para se conectar determinados vértices se justificam pelo seguinte aspecto geométrico da construção do grafo: digamos que tivéssemos um modelo físico de arame da poligonal da figura 3.4, e usássemos uma 

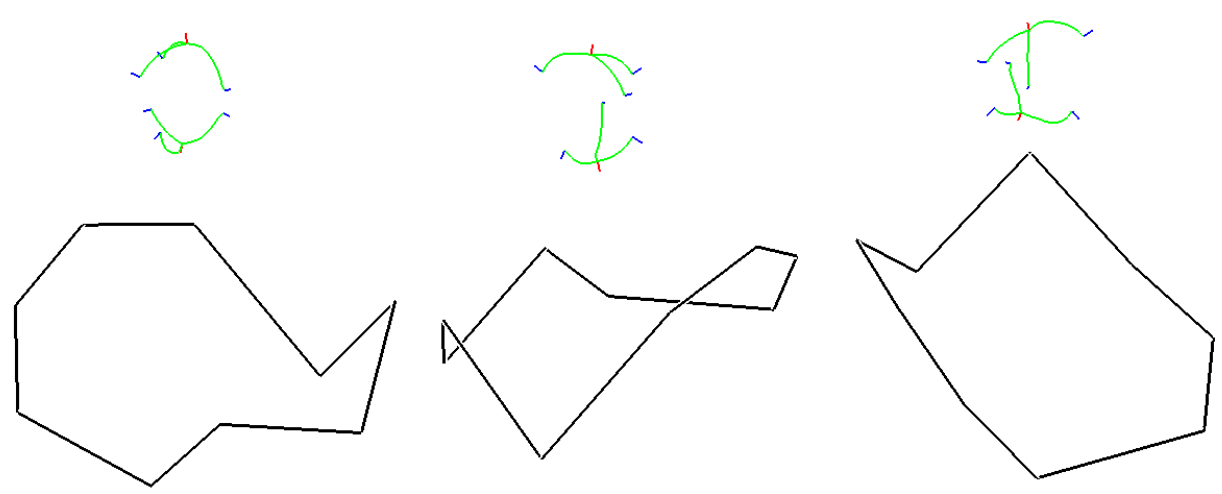

Figura 3.6: Ligando os vértices segundo a regra dos dois vértices (não consecutivos) em comum. Diversos ângulos da mesma poligonal $P$ e de seu grafo $G(P)$.

superfície lisa para simular um plano-suporte. Posicionando essa superfície de forma a obter o plano osculador em azul, podemos obter o plano tritangente (em vermelho) descolando a superfície apenas do vértice 2 e inclinando-a até tocar um outro vértice, no caso o 5 . Repetindo o processo, mas dessa vez mantendo somente os vértices 1 e 5 encostados, a superfície tocará o vértice 9 , obtendo então um plano bitangente (em verde).

O fato de desejarmos que os dois vértices de apoio da superfície se movendo não sejam consecutivos reside no fato de que o grafo que obteríamos seria muito maior e não refletiria certas propriedades geométricas da poligonal nas quais estamos interessados.

A partir do grafo esférico $G(P)$, obtemos o Grafo de Maxwell, denotado por $G_{M}(P)$, cujos vértices são apenas as extremidades das normais aos planos tritangentes e osculadores. As extremidades dos normais aos planos bitangentes, por sua vez, farão parte das arestas.

Observação 3.2.1 No processo físico de inclinação da superfície, obtemos uma infinidade de planos-suporte do tipo $2 / 2$, cujos vetores normais são justamente os pontos das arestas do grafo $G(P)$. No grafo de Maxwell $G_{M}(P)$, ao considerarmos como parte das arestas os vetores normais aos planos bitangentes, se torna razoável considerar também os planos do tipo $2 / 2$ como bitangentes. A distinção anterior se fazia necessária para que a construção do grafo $G(P)$ fosse possível.

A figura 3.7 ilustra vários exemplos dessa construção. As cores aparecem meramente para facilitar a visualização. 

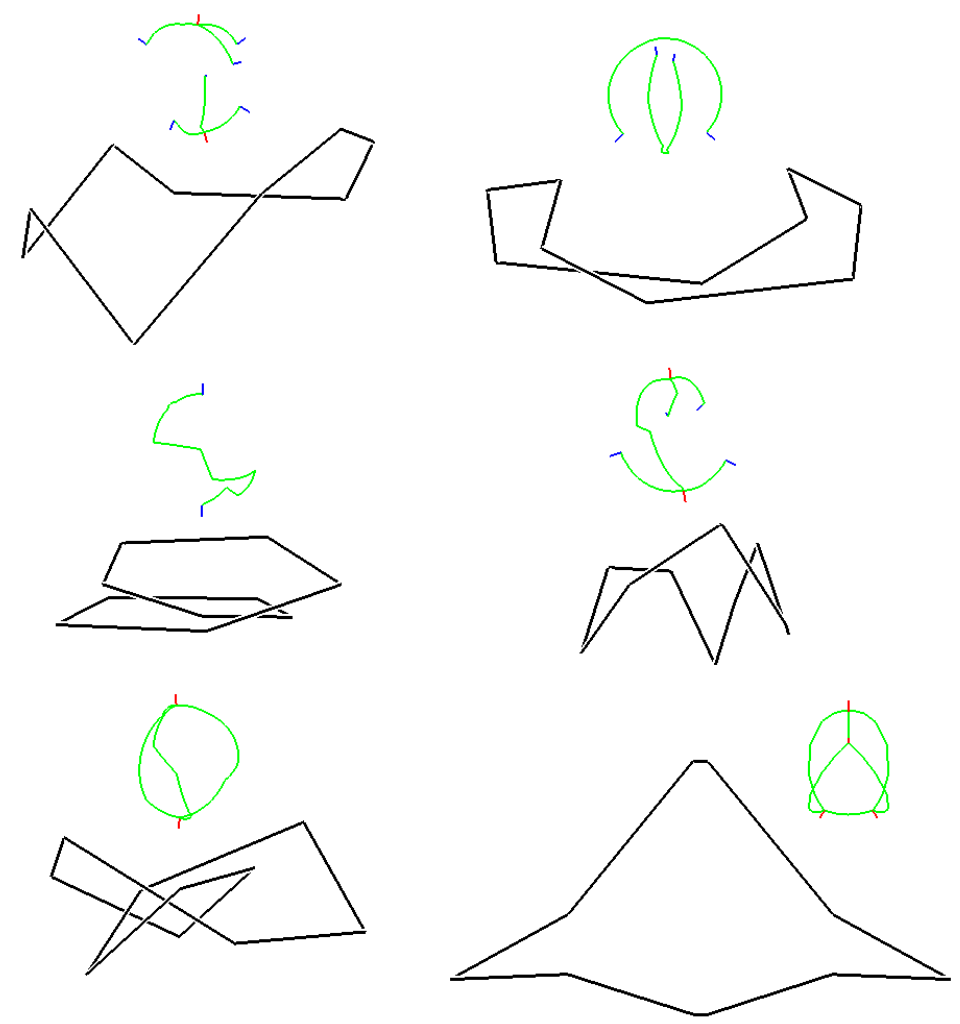

Figura 3.7: Diversas poligonais com seus respectivos grafos de Maxwell. A do canto superior esquerdo é a mesma da figura 3.6.

\section{3}

\section{Relações entre a fronteira do fecho convexo e o Grafo de Maxwell}

Pela construção anterior, temos a seguinte função entre os elementos da triangulação do fecho convexo $\partial H(P)$ e o grafo $G(P)$ :

$$
\Gamma:\{\text { triângulos de } \partial H(P)\} \longrightarrow\{\text { vértices de } G(P)\}
$$

Lema 3.4 A função $\Gamma$ é uma bijeção.

Prova. $\Gamma$ é sobrejetiva por construção. Provemos a injetividade. Com efeito, sejam dois triângulos $\Delta(a, b, c), \Delta(d, e, f)$ com vetor normal $n$ apontando para o semi-espaço contendo a poligonal.

Note que, como $\Pi(a, b, c), \Pi(d, e, f)$ são planos-suporte, os pontos $a, b, c$, $d, e, f$ são mínimos da função altura $\delta_{n}: P \longrightarrow \mathbb{R}$, dada por $\delta_{n}(p)=p \cdot n$. Portanto, pertencem ao mesmo plano. Pela condição de genericidade da poligonal, $\{a, b, c\}=\{d, e, f\}$. Assim, $\Delta(a, b, c)=\Delta(d, e, f)$.

$\Gamma$ é, dessa forma, uma bijeção. Podemos estendê-la a outros elementos da triangulação. Seja $A$ uma aresta comum a dois triângulos $\Delta_{1}, \Delta_{2}$ que não esteja em $P$. Sejam $n_{1}, n_{2}$ as respectivas normais a esses triângulos. Como $\Delta_{1}$ 
e $\Delta_{2}$ possuem dois vértices $v_{i}, v_{j}$ em comum, $n_{1}$ e $n_{2}$ estão ligados em $G(P)$ por um segmento esférico $m$. A relação entre $A$ e $m$ é a seguinte: seguindo a ideia anterior do modelo físico da poligonal, existe uma infinidade de planossuporte do tipo $2 / 2$ contendo os vértices $v_{i}, v_{j}$, obtidos a partir da inclinação da superfície lisa. Para cada um desses planos $\Pi_{\alpha}$, o vetor normal correspondente é um ponto $n_{\alpha}$ da aresta $m$. Pomos então $\Gamma\left(\Pi_{\alpha}\right)=n_{\alpha}$. Além disso, por conveniência, pomos também $\Gamma(A)=m$.

Denote por $S(P):=\partial H(P)-\operatorname{Ext}(P)$ a parte da fronteira do fecho convexo que não intersecta a poligonal. Como estendemos a função $\Gamma$ para as arestas de $H(P)$ que não estão contidas em $P$, obtemos o seguinte

\section{Corolário 3.5}

$\Gamma:\{$ triângulos e arestas de $\partial H(P)-\operatorname{Ext}(P)\} \longrightarrow\{$ vértices e arestas de $G(P)\}$,

a função extendida, também é uma bijeção.

Prova. $\Gamma$ é sobrejetiva por construção. Também é injetiva: dadas duas arestas $A, B \in S(P)$, se $\Gamma(A)=\Gamma(B)=m \in G(P)$, então $m$ conecta dois vértices $n_{1}, n_{2} \in G(P)$. Pelo Lema 3.4, existem somente dois triângulos $\Delta_{1}, \Delta_{2} \in$ $\partial H(P)$ tais que $\Gamma\left(\Delta_{1}\right)=n_{1}$ e $\Gamma\left(\Delta_{2}\right)=n_{2}$, e além disso, pela discussão anterior, $\Delta_{1}$ e $\Delta_{2}$ possuem apenas uma aresta em comum $\Gamma^{-1}(m)$. Portanto, $A=B$.

Proposição 3.6 $\Gamma$ preserva as componentes conexas da triangulação, ou seja, dois triângulos $\Delta_{1}, \Delta_{2}$ estão na mesma componente conexa de $S(P)=$ $\partial H(P)-\operatorname{Ext}(P)$ se e somente se suas respectivas imagens pela função $\Gamma$ estão na mesma componente do grafo $G(P)$.

Prova. Vamos provar que, dados dois triângulos $\Delta_{1}, \Delta_{n}$ em $S(P)$, existe uma sequência de triângulos $\left\{\Delta_{1}, \Delta_{2}, \ldots, \Delta_{n}\right\}$ com uma aresta em comum uma-um ligando $\Delta_{1}$ a $\Delta_{n}$, se e somente se existe uma sequência de vértices $\left\{\Gamma\left(\Delta_{1}\right), \Gamma\left(\Delta_{2}\right), \ldots, \Gamma\left(\Delta_{n}\right)\right\}$ conectados um-a-um ligando $\Gamma\left(\Delta_{1}\right)$ a $\Gamma\left(\Delta_{n}\right)$. A prova é por indução no número $k \in \mathbb{N}$ de elementos da sequência (o número para ambas as sequências é o mesmo devido ao fato de $\Gamma$ ser uma bijeção).

Se $k=2$ (onde $\Delta_{1}$ e $\Delta_{2}$ são os únicos elementos da sequência), então, pela discussão anterior da extensão de $\Gamma$ às arestas de $S(P), \Delta_{1}$ e $\Delta_{2}$ possuem uma aresta $A$ em comum se, e somente se, $\Gamma\left(\Delta_{1}\right)$ e $\Gamma\left(\Delta_{2}\right)$ estão conectados pela aresta $\Gamma(A)$.

Assuma agora a hipótese de indução para $k<n$. Para dois triângulos $\Delta_{1}, \Delta_{n} \in S(P)$ :

existe uma sequência $\left\{\Delta_{1}, \Delta_{2}, \ldots, \Delta_{n}\right\}$ ligando $\Delta_{1}$ a $\Delta_{n}$ 
$\Longleftrightarrow\left\{\Delta_{1}, \Delta_{2}, \ldots, \Delta_{n-1}\right\}$ liga $\Delta_{1}$ a $\Delta_{n-1}$, e $\left\{\Delta_{n-1}, \Delta_{n}\right\}$ liga $\Delta_{n-1}$ a $\Delta_{n}$ $\Longleftrightarrow\left\{\Gamma\left(\Delta_{1}\right), \Gamma\left(\Delta_{2}\right), \ldots, \Gamma\left(\Delta_{n-1}\right)\right\}$ liga $\Gamma\left(\left(\Delta_{1}\right)\right.$ a $\Gamma\left(\Delta_{n-1}\right)$

e $\left\{\Gamma\left(\Delta_{n-1}\right), \Gamma\left(\Delta_{n}\right)\right\}$ liga $\Gamma\left(\Delta_{n-1}\right)$ a $\Gamma\left(\Delta_{n}\right)$, pela hipótese de indução

$\Longleftrightarrow$ existe uma sequência $\left\{\Gamma\left(\Delta_{1}\right), \Gamma\left(\Delta_{2}\right), \ldots, \Gamma\left(\Delta_{n}\right)\right\}$ ligando $\Gamma\left(\Delta_{1}\right)$ a $\Gamma\left(\Delta_{n}\right)$.

Como o grafo $G(P)$ pode ser visto como a imagem da aplicação $\Gamma$ no conjunto de todos os planos-suporte de $P$ das formas $3 / 3,3 / 2,3 / 1$ e $2 / 2$, o mesmo vale para o grafo de Maxwell $G_{M}(P)$, uma vez que ele é, como conjunto, o mesmo que $G(P)$. A diferença reside no fato de que, ao considerarmos o vértices referentes aos planos do tipo $3 / 2$ como parte das arestas, focamos a atenção nos vértices de $G(P)$ com grau de incidência diferente de 2 . Uma reformulação correspondente para os elementos do conjunto $S(P)$ é fornecida pela seguinte

Definição 3.7 Seja $P$ uma poligonal e $G_{M}(P)$ o seu grafo de Maxwell. Definimos painéis como certos subconjuntos de $S(P)=\partial H(P)-\operatorname{Ext}(P)$ (ver figura 3.8):

- Dado um vértice u de $G_{M}(P)$ de grau de incidência igual a 3, chamamos $\Gamma^{-1}(u)$ de um 2-painel de $H(P)$;

- Dada uma aresta e de $G_{M}(P)$, chamamos $\Gamma^{-1}(e)$ de um 1-painel de $H(P)$;

- Dado um vértice u de $G_{M}(P)$ de grau de incidência igual a 1 , chamamos $\Gamma^{-1}(u)$ de um 0 -painel de $H(P)$.
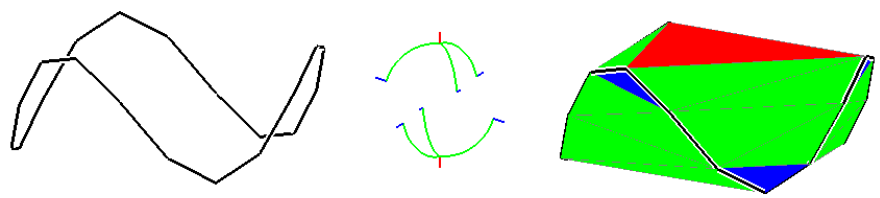

Figura 3.8: Exemplo de poligonal $P$ com seu grafo de Maxwell $G_{M}(P)$ associado, além de seu fecho convexo $H(P)$ com os painéis com cores distintas: vermelho para 2-painéis, verde para 1-painéis e azul para 0-painéis. Lembramos que o vetor $u \in \mathbb{S}^{2}$ no grafo aponta para o semi-espaço contendo a poligonal.

Uma primeira relação entre uma poligonal fechada simples $P$ e seu grafo de Maxwell $G_{M}(P)$ associado está na seguinte 


\section{Proposição 3.8}

(a) $G_{M}(P)$ possui no máximo duas componentes;

(b) $P$ é convexa se e somente se $G_{M}(P)$ possui exatamente duas componentes.

Prova. Pela proposição 3.6 anterior, o número de componentes de $G_{M}(P)$ é o mesmo de $S(P)=\partial H(P)-\operatorname{Ext}(P)$. Como $\partial H(P)$ é homeomorfa à esfera $\mathbb{S}^{2}$ (denote esse homeomorfismo por $\phi: \partial H(P) \longrightarrow \mathbb{S}^{2}$ ), o número de componentes de $S(P)$ é o mesmo número de componentes de $\mathbb{S}^{2}-\phi(\operatorname{Ext}(P))$.

Se $P$ for convexa, então $\operatorname{Ext}(P)=P$. Neste caso, como $P$ é curva simples fechada, $\phi(\operatorname{Ext}(P))=\phi(P)$ também o é. Logo, pelo Teorema da Curva de Jordan (Teorema 4.9), $\mathbb{S}^{2}-\phi(\operatorname{Ext}(P))$ possui exatamente duas componentes. Portanto, $S(P)=\partial H(P)-\operatorname{Ext}(P)$ também possui exatamente duas componentes.

Se $P$ não for convexa, $\operatorname{Ext}(P)$ consiste na união disjunta de uma quantidade finita de curvas poligonais (simples) não fechadas, e assim $\phi(\operatorname{Ext}(P))$ também o é. Pelo Corolário 4.13, $\mathbb{S}^{2}-\phi(\operatorname{Ext}(P))$ possui exatamente 1 componente. Portanto, $S(P)=\partial H(P)-\operatorname{Ext}(P)$ também terá exatamente 1 componente.

Proposição 3.9 Se $P$ é convexa, então cada componente de $G_{M}(P)$ é simplesmente conexa.

Prova. Como $G_{M}(P)$ é um grafo, provar que suas componentes são simplesmente conexas é o mesmo que provar que ambas são árvores. Basta provar, então, que elas não contém ciclos.

Suponha, por absurdo, que haja um ciclo em uma das componentes $G_{M}(P)$. Pela bijeção $\Gamma$ entre $S(P)$ e o grafo $G(P)$ e pela proposição 3.6, temos que existe em $\partial H(P)$ uma região em uma das formas mostradas na figura 3.9: um vértice de $P$ isolado em $\partial H(P)$, ou então uma sequência de vértices de $P$ formando uma curva poligonal não-fechada. Em ambos os casos temos que uma parte da poligonal $P$ se encontra no interior do conjunto $H(P)$, ou seja, $P \not \subset \partial H(P)$. Mas isso contradiz a hipótese de a poligonal ser convexa.

Definição 3.10 Dada uma poligonal fechada simples $P$, seja $\Pi(a, b, c)$ um plano osculador de $P$, ou seja, $\Pi(a, b, c)=\Pi\left(v_{i-1}, v_{i}, v_{i+1}\right)$, para algum $i \in\{1, \ldots, n\}$. Dizemos então que $v_{i}$ é um vértice-suporte de P.

Corolário 3.11 (Teorema dos Quatro Vértices) Se uma poligonal $P$ é convexa e possui ao menos 4 vértices, então possui ao menos 4 vértices-suporte. 


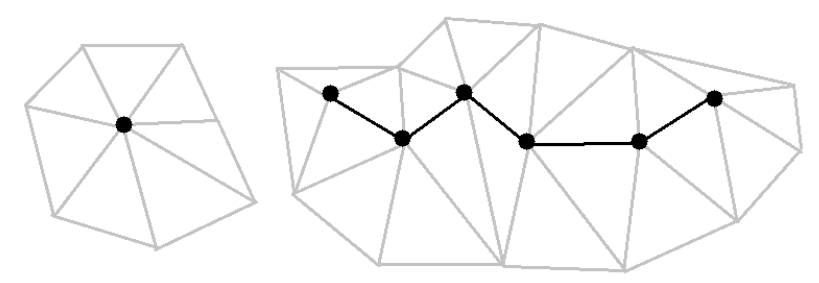

Figura 3.9: Pré-imagem de um ciclo em um grafo de Maxwell: um vértice isolado ou uma curva poligonal não fechada.

Prova. O número de vértices-suporte é o mesmo que o de planos osculadores, que por sua vez é o mesmo que o de vértices no grafo de Maxwell com grau de incidência igual a 1. Provemos que este é maior ou igual a 4.

Se $P$ é convexa, então, pela Proposição $3.8, G_{M}(P)$ possui duas componentes. Pela Proposição 3.9, cada uma delas é uma árvore (não-trivial, pois a poligonal possui pelo menos 4 vértices e consequentemente $\partial H(P)$ terá uma triangulação com pelo menos 4 triângulos). Em uma árvore não-trivial, sempre há ao menos dois pontos com grau de incidência igual a 1 (pelo Teorema 4.21). Segue-se que há pelo menos 4 de tais pontos.

\section{4}

\section{Classificação de pontos do fecho convexo}

Podemos classificar os pontos do envoltório convexo $\partial H(P)$ (segundo a classificação dada em (Fu) e (BF93)) em seis tipos (ver figura 3.10):

- $V_{1}$ : pontos do interior dos 1-painéis e 2-painéis, onde consideramos a topologia do subespaço $\partial H(P)$;

- $V_{2}$ : pontos da fronteira entre painéis em $\partial H(P)-\operatorname{Ext}(P)$;

- $V_{3}$ : pontos das arestas de $P$; vértices $v_{i} \in P$ que não estão contidos em nenhum plano tritangente, e além disso de forma que $v_{i-1}, v_{i+1} \in$ $\operatorname{Ext}(H)$;

- $V_{4}$ : vértices $v_{i} \in P$ que não estão contidos em nenhum plano tritangente, e além disso de forma que $v_{i-1}$ e $v_{i+1}$ sejam tais que um pertença a $\operatorname{Ext}(\mathrm{H})$, e o outro não;

- $V_{5}$ : vértices $v_{i} \in P$ contidos em algum plano tritangente, e além disso de forma que $v_{i-1}$ e $v_{i+1}$ sejam tais que um pertença a $\operatorname{Ext}(\mathrm{H})$, e o outro não;

- $V_{6}$ : vértices $v_{i} \in P$ contidos em algum plano tritangente, e além disso de forma que $v_{i-1}, v_{i+1} \in \operatorname{Ext}(H)$. 

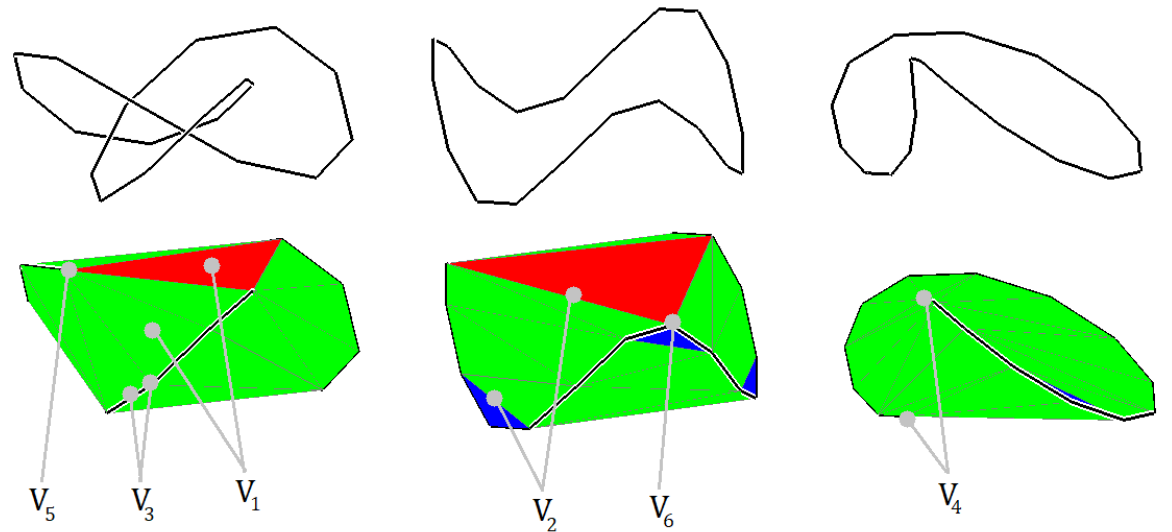

Figura 3.10: Para três poligonais diferentes, seus fechos convexos e exemplos de tipos de pontos segundo a classificação. As cores representam painéis distintos: vermelho para 2-painéis, verde para 1-painéis e azul para 0-painéis.

Denote por $N_{i}$ o número de vértices de $V_{i}$. Temos então as seguintes relações numéricas:

- Se $P$ não for convexa, então $N_{4}+N_{5}=2 \rho$, onde $\rho$ é o número de componentes conexas de $\operatorname{Ext}(P)$.

Com efeito, se $P$ não é convexa, então todas as componentes de $\operatorname{Ext}(P)$ são caminhos poligonais não-fechados, logo possuem um vértice inicial e um final distintos. Se há $\rho$ componentes, então há $2 \rho$ de tais vértices. Por outro lado, pela classificação anterior, o conjunto desses vértices é justamente $V_{4} \cup V_{5}$, e possui assim $N_{4}+N_{5}$ elementos.

- Se todos os triângulos referentes a planos tritangentes forem disjuntos dois-a-dois (dito de modo mais simples, quaisquer de tais triângulos não são adjacentes), então $N_{5}+N_{6}=3 T$, onde $T$ é o número de planos tritangentes. O argumento é análogo ao do item anterior.

\section{5}

\section{Relações numéricas}

Nesta seção fornecemos algumas fórmulas relacionando a quantidade de planos tritangentes, dos planos osculadores, das componentes da parte externa da poligonal e dos vértices considerados na seção anterior.

Dado um grafo de Maxwell $G_{M}(P)$ para uma poligonal $P$, denote por $V$ o número de vértices, $T$ o número de vértices com grau de incidência igual a 3 (que é o mesmo número de planos tritangentes de $P$ ), $C$ o número de vértices com grau de incidência igual a 1 (que é o mesmo número de planos osculadores de $P$ ), e $E$ o número de arestas em $G$. Vale a seguinte: 
Proposição 3.12 Em Grafos de Maxwell, vale que

$$
\begin{gathered}
T+C=V \\
3 T+C=2 E
\end{gathered}
$$

Prova. A primeira igualdade segue-se do fato de termos desconsiderado os vértices de grau de incidência 2 na passagem do grafo $G(P)$ ao $G_{M}(P)$, só restando os de grau 1 e 3.

Para a segunda igualdade, contamos o número de arestas através do número de vértices, o que fornece a expressão à esquerda da igualdade. Deste modo, contudo, acabamos contanto o número de arestas o dobro de vezes.

\subsection{1}

\section{Poligonais convexas}

Como visto anteriormente, o Grafo de Maxwell de uma poligonal $P$ convexa contém duas componentes, ambas árvores. Assim, para $G_{M}(P)$, temos que (pelo Corolário 4.19):

$$
T+C=V=2+E .
$$

Além disso, pela Proposição 3.12:

$$
2 E=3 T+C
$$

Multiplicando a primeira igualdade por 2, substituindo nela $2 E$ por $3 T+C$ e simplificando, obtemos o seguinte:

Teorema 3.13 Dada qualquer poligonal $P$ convexa, temos que

$$
C-T=4
$$

onde $T=$ número total de planos tritangentes, e $C=$ número total de planos osculadores (ou, equivalentemente, de vértices-suporte) da poligonal.

Observação 3.5.1 Note que, deste último resultado, o Teorema dos Quatro Vértices é imediato: $C=T+4 \geq 4$. 


\section{5 .2}

\section{Poligonais não-convexas}

Como visto anteriormente, o Grafo de Maxwell $G_{M}(P)$ de uma poligonal $P$ não-convexa consiste em apenas uma componente. Lembre que $\rho$ representa o número de componentes de $\operatorname{Ext}(P)$. Pela bijeção $\Gamma$ entre $\partial H(P)-\operatorname{Ext}(P)$ e $G_{M}(P)$, temos que $\rho$ também é o número de componentes conexas de $\mathbb{S}^{2}-G_{M}(P)$. (A princípio, também poderíamos estender a função $\Gamma$ para planossuporte do tipo $2 / 1$, o que resultaria em um grafo onde todos os vértices teriam grau de incidência igual a 3. Ainda poderíamos estender essa nova função para planos-suporte do tipo $1 / 1$, o que faria que com que a imagem de $\Gamma$ incluísse toda a esfera $\mathbb{S}^{2}$ ). Isso determina uma estrutura de CW-Complexo na esfera $\mathbb{S}^{2}$, onde os vértices do grafo $G_{M}(P)$ são as 0-células, as arestas de $G_{M}(P)$ são as 1-células e as componentes de $\mathbb{S}^{2}-G_{M}(P)$ (isto é, as faces) são as 2-células. Como há $V=T+C$ vértices, $E$ arestas e $\rho$ componentes do complementar do grafo na esfera, temos, pela Característica de Euler (Teorema 4.23) para a esfera:

$$
T+C-E+\rho=V-E+\rho=2 \text {. }
$$

Além disso, pela Proposição 3.12:

$$
2 E=3 T+C
$$

Multiplicando a primeira igualdade por 2, substituindo nela $2 E$ por $3 T+C$ e simplificando, obtemos o seguinte:

Teorema 3.14 Dada qualquer poligonal $P$ não-convexa, temos que

$$
C-T=4-2 \rho,
$$

onde $T=$ número total de planos tritangentes, $C=$ número total de planos osculadores (ou, equivalentemente, de vértices-suporte) da poligonal e $\rho=$ número de componentes conexas de $\operatorname{Ext}(P)$.

Na seção anterior, vimos que $N_{4}+N_{5}=2 \rho$, e que $N_{5}+N_{6}=3 T$. Multiplicando a igualdade do teorema anterior por 3 , substituindo nela esses valores e simplificando, obtemos o seguinte

Corolário 3.15 Assuma as mesmas hipóteses e convenções do teorema anterior. Suponha ainda que não haja dois planos tritangentes adjacentes. Temos então que

$$
3 C=12-2 N_{4}-2 N_{5}+N_{6},
$$

onde $N_{i}$ representa o número de pontos de pontos do tipo $V_{i}$, para $i \in\{4,5,6\}$. 


\section{6}

\section{Exemplos interessantes de poligonais}

Munidos das equações da seção anterior, examinemos alguns exemplos de poligonais. No caso, utilizamos poligonais que aproximam certas curvas, dadas por equações paramétricas. Para cada caso informamos a curva, junto com o número de pontos utilizado. Há uma imagem para exemplo com a poligonal $P$, seu Grafo de Maxwell $G_{M}(P)$ associado e a fronteira do seu fecho convexo $\partial H(P)$.

Para facilitar a visualização, inserimos novamente na imagem a exibição de $\partial H(P)$ sem a parte superior. Além disso, os painéis de $\partial H(P)$ aparecem com cores diferentes: vermelho para 2-painéis, verde para 1-painéis e azul para 0 -painéis. As imagens dos painés pela função $\Gamma$ no grafo $G_{M}(P)$ recebem a mesma cor que eles: vermelho para vértices de grau de incidência 3 , verde para arestas e azul para vértices de grau de incidência 1.

Novamente, $T$ representa o número de planos tritangentes da poligonal, $C$ o número de planos osculadores e $\rho$ o número de componentes da parte externa da poligonal.

Exemplo 3.6.1 (Curva convexa típica) Usamos a curva $\alpha:[0,2 \pi] \longrightarrow$ $\mathbb{R}^{3}$, dada por

$$
\alpha(t)=(\cos (t), \sin (t), \epsilon \sin (k t)),
$$

onde $k=2$ ou $k=3$, e $\epsilon$ pequeno, mas nem tanto (digamos, $\epsilon \in\left[\frac{1}{5}, \frac{3}{5}\right]$ ). A discretização contém 20 pontos. A figura 3.11 ilustra a poligonal para $k=2$ (onde $C=4$ e $T=0$ ), enquanto que a figura 3.12 ilustra a poligonal para $k=3$ (onde $C=6$ e $T=2$ ).
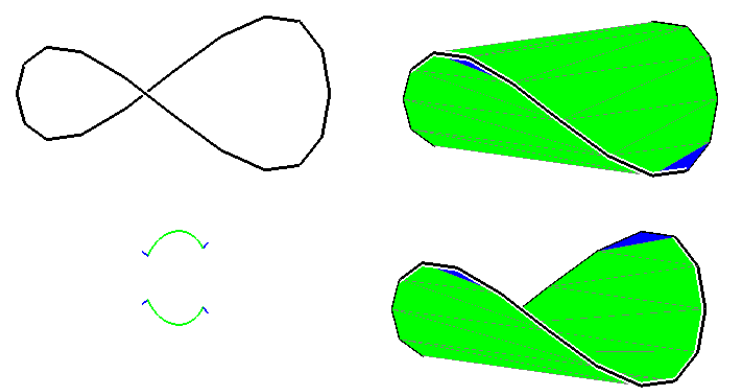

Figura 3.11: Curva convexa típica quando $k=2$. $C=4$ e $T=0$.

Exemplo 3.6.2 (Nó de trevo usual) Usamos a curva $\alpha:[0,2 \pi] \longrightarrow \mathbb{R}^{3}$, dada por

$$
\alpha(t)=(\sin (t)+2 \sin (2 t), \cos (t)-2 \cos (2 t),-\sin (3 t)) .
$$




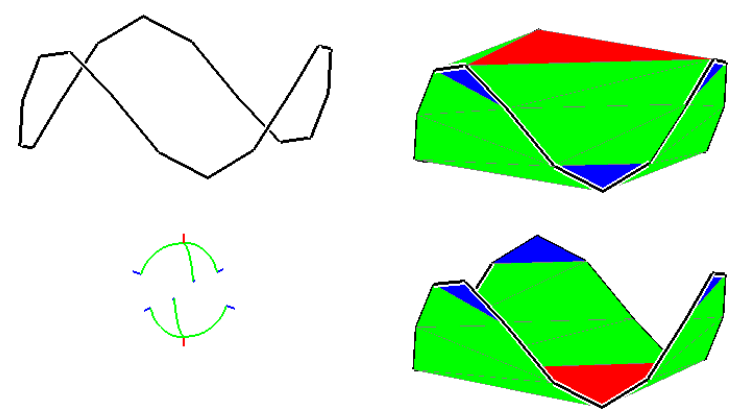

Figura 3.12: Curva convexa típica quando $k=3$. $C=6$ e $T=2$.

A discretização contém 30 pontos e é representada na figura 3.13. Vale a relação numérica para poligonais não-convexas, vista na seção anterior: $C=0$, $T=2$ e $\rho=3$.
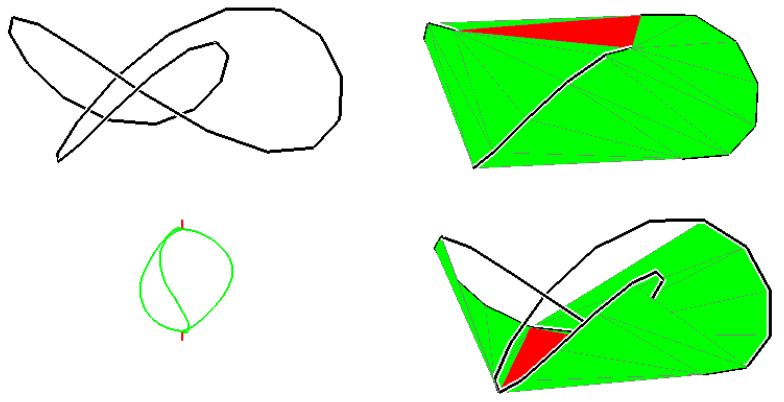

Figura 3.13: Nó de trevo usual. $C=0, T=2$ e $\rho=3$.

Exemplo 3.6.3 Usamos a curva $\alpha:[0,2 \pi] \longrightarrow \mathbb{R}^{3}$, dada por

$$
\alpha(t)=(\sin (t)+2 \sin (2 t), \cos (t)+2 \cos (2 t),-\sin (3 t)) .
$$

A discretização contém 30 pontos e é representada na figura 3.14. É uma poligonal não-convexa, e os números de interesse são $C=0, T=2$ e $\rho=3$. Note que, apesar de esses três números serem os mesmos para o exemplo anterior (o que implica ainda em o número $E$ de arestas do grafo ser o mesmo), os grafos de Maxwell associados não são os mesmos. Neste exemplo os dois vértices são incidentes com eles mesmos. Note ainda que esta poligonal é isotópica ao círculo, e portanto não é um nó.

Exemplo 3.6.4 Usamos a curva $\alpha:[0,2 \pi] \longrightarrow \mathbb{R}^{3}$, dada por

$$
\alpha(t)=(2 \sin (t)-\sin (2 t), 2 \cos (t)-\cos (2 t),-\sin (2 t)) .
$$



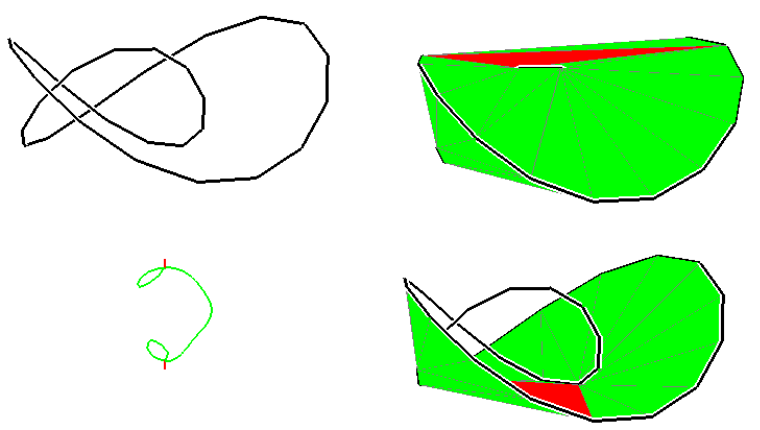

Figura 3.14: Poligonal isotópica ao círculo, porém não-convexa. $C=0, T=2$ e $\rho=3$.

$A$ discretização contém 20 pontos e é representada na figura 3.15. É uma poligonal não-convexa. $C=2, T=0$ e $\rho=1$.
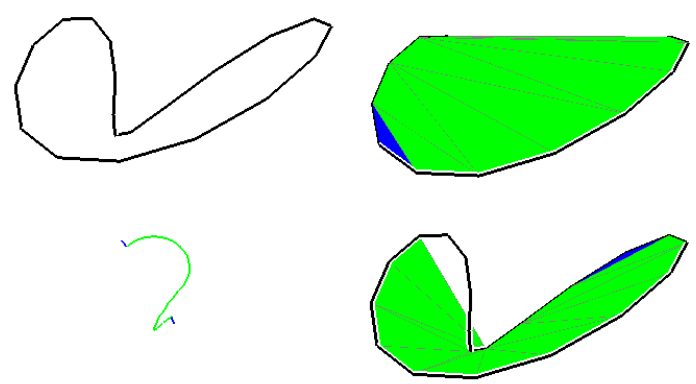

Figura 3.15: Poligonal isotópica ao círculo, porém não-convexa. $C=2, T=0$ e $\rho=1$.

Exemplo 3.6.5 Usamos a curva $\alpha:[0,2 \pi] \longrightarrow \mathbb{R}^{3}$, dada por

$$
\alpha(t)=(3 \cos (t)+\cos (3 t), 3 \sin (t)-\sin (3 t),-\sin (2 t)) .
$$

A discretização contém 20 pontos e é representada na figura 3.16. É uma poligonal convexa. $C=4$ e $T=0$.

Exemplo 3.6.6 Usamos a curva $\alpha:[0,2 \pi] \longrightarrow \mathbb{R}^{3}$, dada por

$$
\alpha(t)=(5 \cos (t)-\cos (3 t), 5 \sin (t)-\sin (3 t),-2 \sin (3 t)) .
$$

A discretização contém 30 pontos e é representada na figura 3.1\%. É uma poligonal não-convexa. $C=2, T=2$ e $\rho=2$. 


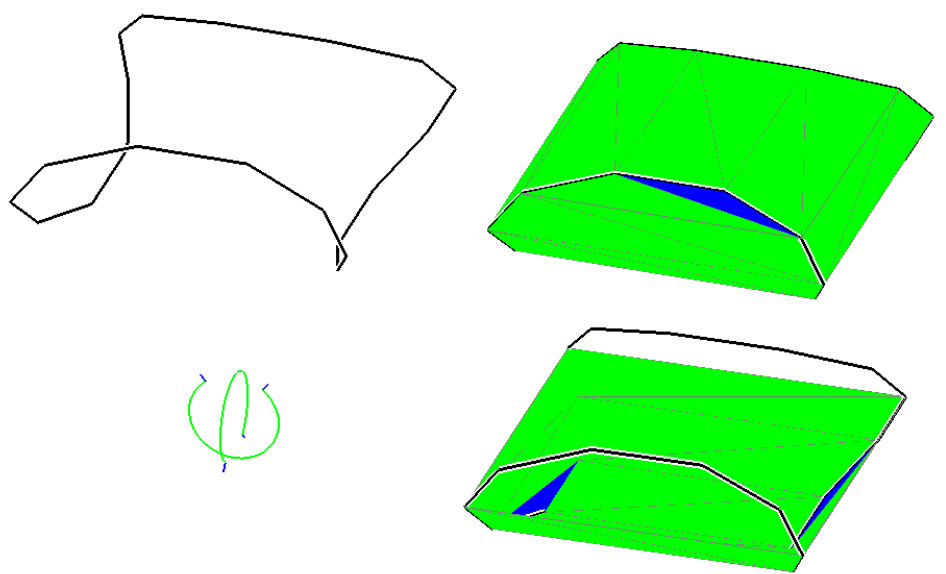

Figura 3.16: Poligonal isotópica ao círculo, convexa. $C=4$ e $T=0$.
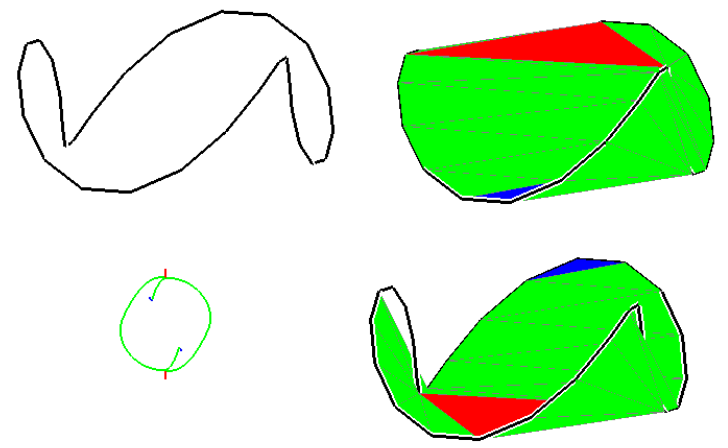

Figura 3.17: Poligonal isotópica ao círculo, não-convexa. $C=2, T=2$ e $\rho=2$.

Exemplo 3.6.7 Usamos a curva $\alpha:[0,2 \pi] \longrightarrow \mathbb{R}^{3}$, dada por

$$
\alpha(t)=\left(\cos (t), \sin (t), 2 \sin (3 t)\left(\frac{t}{2 \pi}\right)\left(1-\frac{t}{2 \pi}\right)\right) .
$$

A discretização contém 30 pontos e é representada na figura 3.18. É uma poligonal convexa, com grafo de Maxwell um pouco mais complexo que o das poligonais convexas anteriores. $C=8$ e $T=4$.

Exemplo 3.6.8 Usamos a curva $\alpha:[0,2 \pi] \longrightarrow \mathbb{R}^{3}$, dada por

$$
\alpha(t)=\left(3 \cos (t), 2 \sin (t), 10 \sin (3 t)\left(\frac{t}{2 \pi}\right)^{2}\left(1-\frac{t}{2 \pi}\right)\right) .
$$

A discretização contém 30 pontos e é representada na figura 3.19. É uma poligonal convexa, cujo grafo de Maxwell possui duas componentes não homeomorfas. Tal característica não tinha aparecido até então em outras poligonais convexas. $C=7$ e $T=3$. 

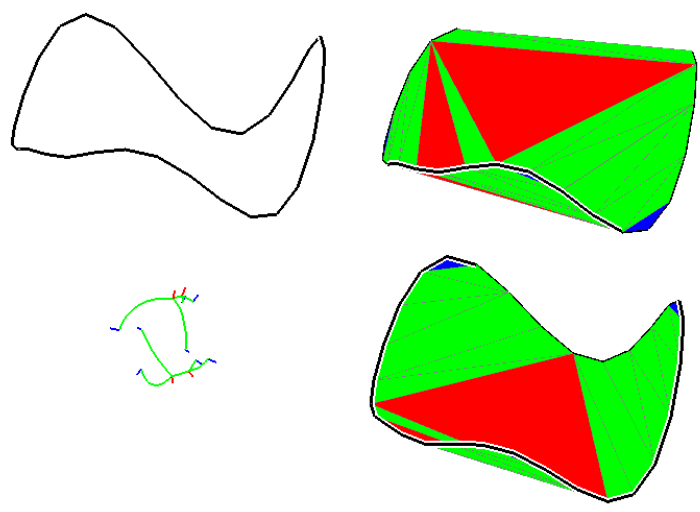

Figura 3.18: Poligonal convexa com grafo de Maxwell mais extenso. $C=8 \mathrm{e}$ $T=4$.

Em (Fu), foi mencionado que, para os exemplos considerados de curvas suaves (satisfazendo às condições de genericidade) convexas, as componentes do grafo de Maxwell associado eram sempre homeomorfas. O presente exemplo é, ao menos para o caso discreto, um contra-exemplo. Note que a curva parametrizada dada acima pode não ser um contra-exemplo no caso suave, uma vez que pode não satisfazer às condições de genericidade em (Fu). Além disso, a discretização depende apenas da escolha de um número finito de pontos (no caso 30), o que é menos restritivo.
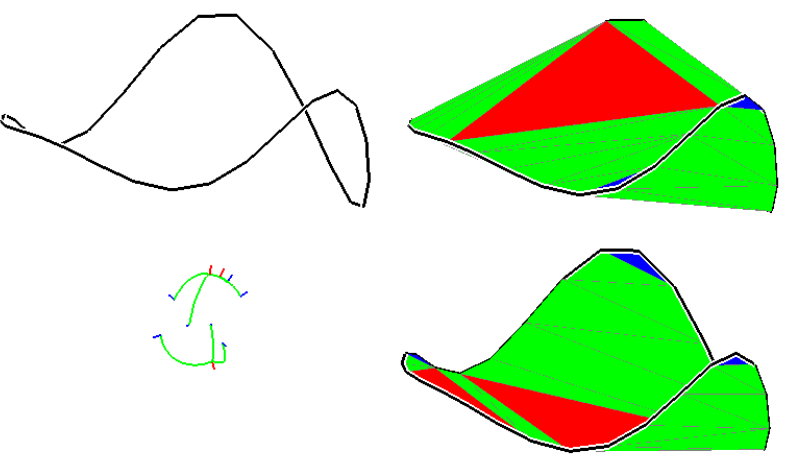

Figura 3.19: Poligonal convexa cujo grafo de Maxwell contém duas componentes não homeomorfas uma à outra. $C=7$ e $T=3$.

Os exemplos anteriores mostraram certa variedade dos grafos de Maxwell de um poligonal. Um exemplo interessante, contudo, é o fornecido pelo seguinte Exemplo 3.6.9 (Nó de toro (3-2)) Usamos a curva $\alpha:[0,2 \pi] \longrightarrow \mathbb{R}^{3}$, dada por

$$
\alpha(t)=((4+\cos (2 t)) \cos (3 t),(4+\cos (2 t)) \sin (3 t), 2 \sin (2 t)) .
$$


A discretização contém 30 pontos e é representada na figura 3.20. Esta poligonal é do mesmo tipo de isotopia que o nó de trevo (veja (CF) (pág. 92) ou (Mur) (pág. 136)). Contudo, surpreendentemente, $T=0$ e $C=0$ (o que não contradiz a fórmula obtida anteriormente, uma vez que $\rho=2$ ), o que não esperaríamos, pelo menos a princípio, para nós equivalentes aos nós de trevo. Além disso, para esta poligonal $P$, o grafo $G(P)$ é um ciclo e, consequentemente, $G_{M}(P)$ não é um grafo propriamente dito (deveria possuir ao menos um vértice), constituindo-se em um caso degenerado.
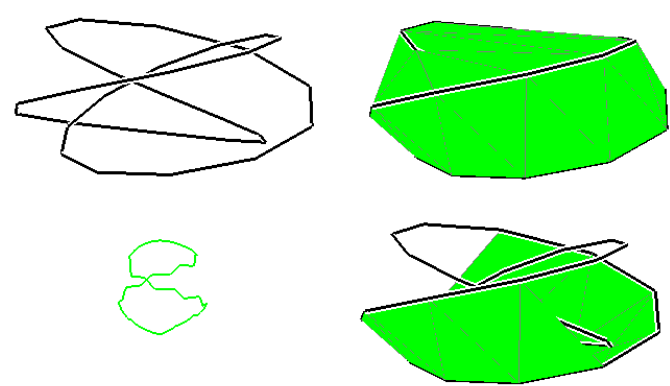

Figura 3.20: Uma poligonal isotópica ao nó de trevo, porém sem planos tritangentes ou osculadores. Importante notar que a "auto-interseção"da aresta do grafo nela mesma é apenas aparente, decorrente da projeção escolhida.

Podemos nos perguntar quais características deve possuir um nó de trevo (ou mais geralmente, um nó) poligonal para admitir uma quantidade mínima de planos tritangentes. Tais questões são abordadas no artigo (Hei). Daremos uma resposta aqui, mas em função do número de planos osculadores da poligonal e do número de componentes de $\operatorname{Ext}(P)$. Como toda poligonal convexa não é um nó, temos que todo nó poligonal é não-convexo. Logo, vale o teorema 3.14:

$$
C-T=4-2 \rho
$$

onde $T$ é o número total de planos tritangentes, $C$ o número total de planos osculadores da poligonal e $\rho$ o número de componentes conexas de $\operatorname{Ext}(P)$. Note que vale sempre $\rho>0$.

Assim, $T=C+2 \rho-4$. Os seguintes casos esgotam as possibilidades para o nó poligonal:

- Como $C-T=4-2 \rho=2(2-\rho), C$ ser ímpar implicará em $T$ ser ímpar, logo diferente de zero;

- Se $C \geq 4, T=4+2 \rho-4=2 \rho>0$;

- Se $C=2, T=2 \rho-2=2(\rho-1)$, que será maior que zero se e somente se $\rho>1$; 
- Se $C=0,2 \rho-4=2(\rho-2)>0$ se e somente se $\rho>2$.

Note que o último caso considerado engloba o nó de trevo usual (figura 3.13), onde $\rho=3$.

Exemplo 3.6.10 (Nó de Listing) Usamos a curva $\alpha:[0,2 \pi] \longrightarrow \mathbb{R}^{3}$, dada por

$$
\alpha(t)=((2+\cos (2 t)) \cos (3 t),(2+\cos (2 t)) \sin (3 t), \sin (4 t)) .
$$

A discretização contém 30 pontos e é representada na figura 3.21. É um nó poligonal (logo, poligonal não-convexa). $C=0, T=8$ e $\rho=6$. Note que na fronteira do fecho convexo da poligonal $\partial H(P)$ há dois pares de triângulos referentes a planos tritangentes com uma aresta em comum. Logo não vale o Corolário 3.15 para este caso, embora ainda valha o Teorema 3.14.
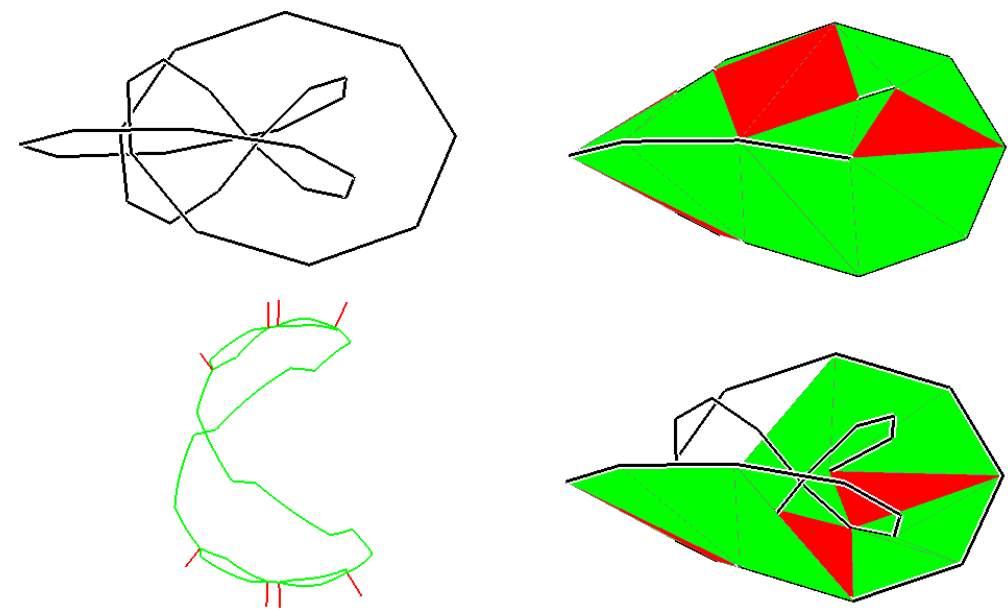

Figura 3.21: Nó de Listing. $C=0, T=8$ e $\rho=6$. Importante notar que a "auto-interseção"da aresta do grafo nela mesma é apenas aparente, decorrente da projeção escolhida. Note ainda que no grafo há dois pares de vértices muito próximos um do outro, porém não iguais. Assim, a condição de a poligonal ser genérica continua sendo preservada. 
Alguns Resultados Básicos

Neste capítulo abordamos conceitos e resultados que foram utilizados nos capítulos anteriores, cujo tratamento adequado exigiria um desvio muito brusco da linha principal de raciocínio. Na maioria dos casos, fornecemos demonstrações completas (para outras, indicamos alguns livros presentes nas Referências Bibliográficas).

\section{1}

\section{Geometria Esférica}

A geometria esférica consiste no modelo usual de geometria elíptica (na qual o Postulado de Euclides das Paralelas é negado da forma "não há retas paralelas"). O espaço ambiente ("plano elíptico") é a esfera $\mathbb{S}^{2}$. Os pontos serão os pontos usuais da esfera. As retas serão os grandes círculos da esfera, ou seja, as interseções da esfera com planos que passam pela origem.

Dois pontos $u, v \in \mathbb{S}^{2}$ são ditos antipodais se $u=-v$. No caso, existe uma infinidade de planos que passam pela origem (logo, de grandes círculos da esfera) que contém ambos os pontos.

Caso contrário, isto é, se $u \neq-v$, então existe somente um plano que passa pela origem e que contém ambos os pontos, a saber, o plano gerado por $\{u, v\}$, onde $u$ e $v$ são considerados como vetores. Neste caso, denotamos o plano por $\Pi_{\nu}$, onde $\nu=u \times v$ vetor normal ao plano. Denotamos ainda por $r_{\nu}=\mathbb{S}^{2} \cap \Pi_{\nu}$ o grande círculo da esfera que contém $u$ e $v$.

Definição 4.1 Dados dois pontos $u, v \in \mathbb{S}^{2}$ não-antipodais, ou seja, $u \neq-v$, seja $\nu=u \times v$. Definimos o segmento esférico entre $u$ e $v$ como o menor arco do grande círculo $r_{\nu}$. Equivalentemente, é o traço do caminho $\alpha:[0,1] \longrightarrow \mathbb{S}^{2}$ parametrizado por

$$
\alpha(t)=\frac{(1-t) u+t v}{|(1-t) u+t v|}, t \in[0,1] .
$$

Estamos interessados em uma função distância entre os pontos da esfera. Primeiramente, observe que, para $u, v \in \mathbb{S}^{2}$, vale que

$$
\cos (\theta(u, v))=\langle u, v\rangle, \sin (\theta(u, v))=\|u \times v\|,
$$

onde $\langle u, v\rangle$ e $u \times v$ são o produto interno e o produto vetorial usuais entre dois vetores $u, v \in \mathbb{S}^{2} \subset \mathbb{R}^{3}$. 
Definição 4.2 Dados $u, v \in \mathbb{S}^{2}$, definimos a distância esférica como a aplicação

$$
d: \mathbb{S}^{2} \times \mathbb{S}^{2} \longrightarrow R, d(u, v)=\theta(u, v)
$$

Proposição 4.3 A função d, definida anteriormente, é uma função distância em $\mathbb{S}^{2}$, ou seja, satisfaz a:

1. $d(u, v) \geq 0, d(u, v)=0 \Longleftrightarrow u=v$;

2. $d(u, v)=d(v, u)$;

3. $d(u, w) \leq d(u, v)+d(v, w)$;

A propriedade (3) é a Desigualdade Triangular Esférica.

Para a prova da proposição, usaremos o mesmo argumento em (BA). Precisamos do seguinte

Lema 4.4 Para quaisquer vetores $u, v, w, t \in \mathbb{R}^{3}$, vale que

$$
\langle u \times v, w \times t\rangle=\operatorname{det}\left[\begin{array}{cc}
\langle u, w\rangle & \langle u, t\rangle \\
\langle v, w\rangle & \langle v, t\rangle
\end{array}\right]=\langle u, w\rangle\langle v, t\rangle-\langle u, t\rangle\langle v, w\rangle .
$$

Prova. A segunda igualdade é clara. A primeira segue-se simplesmente das definições de produto interno e produto vetorial, desenvolvendo-se as contas e verificando-se que ambos os lados são iguais.

Prova. (da Proposição 4.3) Para mostrar (1), note inicialmente que, como $\sin (\theta(u, v))=\|u \times v\| \geq 0$, então $0 \leq \theta(u, v) \leq \pi$. Além disso:

$$
\begin{gathered}
\theta(u, v)=0 \Longleftrightarrow\langle u, v\rangle=\cos (0)=1 \text { e }\|u \times v\|=\sin (0)=0 \\
\Longleftrightarrow\langle u, v\rangle=1 \text { e } v=\lambda u, \text { para algum } \lambda \in \mathbb{R} \\
\Longleftrightarrow u=v .
\end{gathered}
$$

(2) segue-se do fato de que $\cos (\theta(u, v))=\langle u, v\rangle=\langle v, u\rangle=\cos (\theta(v, u))$, e de que $v \times u=-u \times v$, donde $\sin (\theta(u, v))=\|u \times v\|=|-1| \cdot\|u \times v\|=$ $\|v \times u\|=\sin (\theta(v, u))$.

(3) exige alguns truques. Queremos mostrar que

$$
\theta(u, w) \leq \theta(u, v)+\theta(v, w)
$$


Se vale que $\pi \leq \theta(u, v)+\theta(v, w)$, então temos que $\theta(u, w) \leq \pi \leq \theta(u, v)+$ $\theta(v, w)$.

Suponhamos então que vale a desigualdade $\theta(u, v)+\theta(v, w) \leq \pi$. Como a função $\cos :[0, \pi] \longrightarrow \mathbb{R}$ é decrescente, então, para demonstrar a desigualdade triangular para $\theta$, basta mostrar a desigualdade

$$
\cos (\theta(u, v)+\theta(v, w)) \leq \cos (\theta(u, w))
$$

Como os vetores são unitários, vale que

$$
\begin{aligned}
\cos (\theta(u, v)+\theta(v, w)) & =\cos (\theta(u, v)) \cos (\theta(v, w))-\sin (\theta(u, v)) \sin (\theta(v, w)) \\
= & \langle u, v\rangle\langle v, w\rangle-\|u \times v\|\|v \times w\|
\end{aligned}
$$

Pela Desigualdade de Cauchy-Schwarz:

$$
-\langle u \times v, v \times w\rangle \geq-\|u \times v\|\|v \times w\|
$$

Pelo Lema 4.4:

$$
\langle u \times v, v \times w\rangle=\operatorname{det}\left[\begin{array}{cc}
\langle u, v\rangle & \langle u, w\rangle \\
\langle v, v\rangle & \langle v, w\rangle
\end{array}\right]=\langle u, v\rangle\langle v, w\rangle-\langle u, w\rangle\langle v, v\rangle .
$$

Como $|v|=1$, obtemos:

$$
\begin{gathered}
\cos (\theta(u, v)+\theta(v, w))=\langle u, v\rangle\langle v, w\rangle-\|u \times v\|\|v \times w\| \\
\leq\langle u, v\rangle\langle v, w\rangle-\langle u \times v, v \times w\rangle \\
=\langle u, v\rangle\langle v, w\rangle-(\langle u, v\rangle\langle v, w\rangle-\langle u, w\rangle\langle v, v\rangle) \\
=\langle u, v\rangle\langle v, w\rangle-\langle u, v\rangle\langle v, w\rangle+\langle u, w\rangle \cdot 1 \\
=\langle u, w\rangle \\
\cos (\theta(u, w)),
\end{gathered}
$$

o que conclui a demonstração.

Para mais detalhes quanto à geometria esférica, recomendamos (BA).

\section{2}

\section{A Propriedade da Interseção Finita para Espaços Compactos}

Nesta pequena seção, damos uma formulação alternativa para um espaço compacto. Para tal, seguimos a apresentação dada em (Mun). Primeiramente, alguns conceitos básicos de topologia: 
Definição 4.5 Seja X um espaço topológico. Uma coleção $\mathcal{A}$ de subconjuntos de $X$ é dita uma cobertura de $X$, se a união dos elementos de $\mathcal{A}$ é igual a $X$. É chamada de uma cobertura aberta se todos os elementos são subconjuntos abertos de $X$.

Definição 4.6 Um espaço $X$ é dito compacto se toda cobertura aberta $\mathcal{A}$ contém uma subcobertura finita que também cobre $X$.

Definição 4.7 Uma coleção $\mathcal{C}$ de subconjuntos de $X$ possui a propriedade da interseção finita se, para toda subcoleção finita

$$
\left\{C_{1}, \ldots, C_{n}\right\}
$$

de $\mathcal{C}$, a interseção $C_{1} \cap \ldots \cap C_{n}$ é não-vazia.

Um reformulação para conjuntos compactos é dada pelo seguinte

Teorema 4.8 Seja $X$ um espaço topológico. Então $X$ é compacto se, e somente se, para toda coleção $\mathcal{C}$ de subconjuntos fechados de $X$ possuindo a propriedade da interseção finita, a interseção $\cap_{C \in \mathcal{C}} C$ de todos os elementos de $\mathcal{C}$ é não-vazia.

Prova. Dada uma coleção $\mathcal{A}$ de subconjuntos de $X$, seja

$$
\mathcal{C}=\{X-A \mid A \in \mathcal{A}\}
$$

a coleção de seus complementos. Valem as seguintes afirmações:

(1) $\mathcal{A}$ é uma coleção de conjuntos abertos se e somente se $\mathcal{C}$ é uma coleção de conjuntos fechados.

(2) A coleção $\mathcal{A}$ cobre $X$ se e somente se a interseção $\cap_{C \in \mathcal{C}} C$ se todos os elementos de $\mathcal{C}$ é vazia.

(3) A subcoleção finita $\left\{A_{1}, \ldots, A_{n}\right\}$ de $\mathcal{A}$ cobre $X$ se e somente se a interseção dos elementos correspondentes $C_{i}=X-A_{i}$ é vazia.

(1) é trivial. (2) e (3) seguem-se da Lei de DeMorgan:

$$
X-\left(\bigcup_{\lambda \in J} A_{\lambda}\right)=\bigcap_{\lambda \in J}\left(X-A_{\lambda}\right)
$$

A afirmação de que $X$ é compacto é equivalente a dizer que: "Dada qualquer coleção $\mathcal{A}$ de abertos de $X$, se $\mathcal{A}$ cobre $X$, então alguma coleção finita de $\mathcal{A}$ cobre $X^{\prime \prime}$. Essa afirmação é equivalente à sua contra-positiva, 
que é a seguinte: "Dada qualquer coleção $\mathcal{A}$ de abertos de $X$, se nenhuma subcoleção finita de $\mathcal{A}$ cobre $X$, então $\mathcal{A}$ não cobre $X^{\prime \prime}$. Pondo $\mathcal{C}$ como a coleção $\{X-A \mid A \in \mathcal{A}\}$, e usando (1)-(3), a última afirmação é então equivalente à seguinte: "Dada qualquer coleção $\mathcal{C}$ de fechados de $X$, se toda interseção finita de elementos de $\mathcal{C}$ é não-vazia, então a interseção de todos os elementos de $\mathcal{C}$ é não-vazia". Esta é justamente a condição do teorema.

\section{3}

\section{O Teorema da Curva de Jordan}

Um fato fundamental sobre a esfera $\mathbb{S}^{2}$ (e o plano $\mathbb{R}^{2}$ ) é o de que, dada qualquer curva $\alpha$ simples e fechada contida em $\mathbb{S}^{2}$ (e em $\mathbb{R}^{2}$ ), $\alpha$ a separa em duas componentes, isto é, $\mathbb{S}^{2}-\alpha$ consiste em duas componentes. Este é o conteúdo do Teorema da Curva de Jordan. Para a teoria subjacente a este assunto e demonstrações dos teoremas a seguir, indicamos (Mun) (págs. 376-393).

Teorema 4.9 (Teorema da Curva de Jordan) Seja a uma curva simples fechada (ou seja, homeomorfa a $\mathbb{S}^{1}$ ) em $\mathbb{S}^{2}$. Então $\alpha$ separa $\mathbb{S}^{2}$ em precisamente duas componentes $W_{1}$ e $W_{2}$. Além disso, cada um dos conjuntos $W_{1}$ e $W_{2}$ possuem $\alpha$ como fronteira.

Se a curva $\alpha$, contudo, não for fechada, temos o seguinte:

Teorema 4.10 Seja $\alpha$ uma curva simples não-fechada (ou seja, homeomorfa $a[0,1])$ em $\mathbb{S}^{2}$. Então, $\alpha$ não separa $\mathbb{S}^{2}$.

Teorema 4.11 Sejam $D_{1}$ e $D_{2}$ subconjuntos fechados de $\mathbb{S}^{2}$ tais que $\mathbb{S}^{2}-D_{1} \cap$ $D_{2}$ é simplesmente conexo. Se nem $D_{1}$ nem $D_{2}$ separa $\mathbb{S}^{2}$, então $D_{1} \cup D_{2}$ não separa $\mathbb{S}^{2}$.

Uma consequência imediata do teorema anterior é o

Corolário 4.12 Sejam $D_{1}$ e $D_{2}$ subconjuntos fechados de $\mathbb{S}^{2}$, com $D_{1} \cap D_{2}=$ $\emptyset$. Se nem $D_{1}$ nem $D_{2}$ separa $\mathbb{S}^{2}$, então $D_{1} \cup D_{2}$ não separa $\mathbb{S}^{2}$.

Aplicando indutivamente o resultado anterior, obtemos então o

Corolário 4.13 Sejam $D_{1}, D_{2}, \ldots, D_{n}$ subconjuntos fechados de $\mathbb{S}^{2}$, disjuntos dois-a-dois. Se nenhum $D_{i}$ separa $\mathbb{S}^{2}$, então $\cup_{i=1}^{n} D_{i}$ não separa $\mathbb{S}^{2}$. 


\section{4 \\ Grafos e Árvores}

Todos os grafos considerados nesta seção são finitos.

Definição 4.14 Um grafo conexo G é chamado de uma árvore se não contém ciclos.

Definição 4.15 Em um grafo $G$, uma folha é um vértice $v$ com grau de incidência igual a 1.

Proposição 4.16 Seja $G$ um grafo onde todos os vértices possuem grau de incidência (ou seja, o número de incidência de cada vértice com arestas) maior ou igual a 2 . Então $G$ contém um ciclo.

Prova. Se $G$ contém um loop (ou seja, aresta incidente apenas com um vértice), contém um ciclo de comprimento 1 , e se $G$ contém arestas paralelas (ou seja, incidentes com os mesmos vértices), contém um ciclo de comprimento 2. Podemos supor, portanto, que $G$ seja simples (isto é, para cada par de vértices, há no máximo uma aresta incidente com ambos).

Seja $P:=v_{0} v_{1} \ldots v_{k-1} v_{k}$ um caminho em $G$ de comprimento máximo (sempre há tal caminho pois $G$ é finito). Como o grau de $v_{k}$ é de pelo menos 2 , possui um vizinho $v$ diferente de $v_{k-1}$. Se $v$ não pertence a $P$, então o caminho $v_{0} v_{1} \ldots v_{k-1} v_{k} v$ contradiz a escolha de $P$ como um caminho de comprimento máximo. Portanto, $v=v_{i}$, para algum $i \in\{0, \ldots, k-2\}$, e assim $v_{i} v_{i+1} \ldots v_{k} v_{i}$ é um ciclo em $G$.

Corolário 4.17 Em uma árvore $G$, existe ao menos uma folha.

Prova. Se não fosse o caso, a preposição anterior implicaria que $G$ contém um ciclo, e portanto não seria uma árvore, contradizendo a hipótese.

Denote por $V$ e $E$ os números de vértices e arestas do grafo $G$, respectivamente. Um resultado importante a respeito de árvores é o seguinte

Teorema 4.18 Se $G$ é uma árvore conexa, então $V=E+1$.

Prova. A prova é por indução no número $V$ de vértices. A árvore trivial (um vértice apenas, sem arestas) satisfaz trivialmente à fórmula. Seja $G$ uma árvore com $V$ vértices. Se $v$ é uma folha de uma árvore $G$, o subgrafo $G-v$ (obtido retirando do grafo $G$ tanto $v$ como a aresta $e$ incidente com o mesmo) é uma árvore, com $V^{\prime}=V-1$ vértices e $E^{\prime}=E-1$ arestas. Daí, pela hipótese de indução para árvores com $(V-1)$ vértices: $V=V^{\prime}+1=E^{\prime}+1+1=E+1$. 
Corolário 4.19 Se o grafo $G$ contém $k$ componentes, e cada uma delas é uma árvore, temos que $V=E+k$.

Uma consequência interessante do teorema anterior é o

Corolário 4.20 Seja uma árvore conexa $G$ com vértices $P_{1}, P_{2}, \ldots, P_{V}$, e sejam $d_{1}, d_{2}, \ldots, d_{V}$ os graus de cada um. Então

$$
d_{1}+d_{2}+\ldots+d_{V}=2(V-1)
$$

Prova. Contamos o número de arestas. Para cada $P_{i}$, há $d_{i}$ arestas que incidem com o mesmo, o que fornece a expressão à esquerda da igualdade. Desse modo, contudo, contamos cada arestas duas vezes. Assim,

$$
d_{1}+d_{2}+\ldots+d_{V}=2 E
$$

Como, pelo teorema anterior, $E=V-1$, segue o resultado.

Corolário 4.21 Seja G uma árvore conexa não-trivial (ou seja, não consiste em apenas um vértice isolado). Então $G$ contém ao menos 2 folhas.

Prova. Suponha, por absurdo, que $G$ possua menos de 2 folhas. Pela primeira proposição desta seção, esse número não pode ser zero. Suponha, então, que haja exatamente 1 folha. Denote esse vértice por $v_{1}$. Temos então que $d_{1}=1$ e, para todo $i \in\{2, \ldots, V\}, d_{i} \geq 2$. Assim:

$$
\sum_{i=1}^{V} d_{i} \geq 1+2(V-1)
$$

Pelo Corolário anterior:

$$
2(V-1)=\sum_{i=1}^{V} d_{i} \geq 1+2(V-1),
$$

donde $0 \geq 1$. Contradição. Portanto, há pelo menos duas folhas em $G$.

Para mais detalhes quanto a árvores e suas propriedades, recomendamos (Hen) e (BM). 


\section{5}

\section{A Característica de Euler}

A conhecida fórmula para poliedros que relaciona o número de suas vértices, arestas e faces, $V-E+F=2$, revela na realidade um invariante relacionado a espaços topológicos homeomorfos à esfera: o número 2 é a característica de Euler $\chi\left(\mathbb{S}^{2}\right)$ da esfera.

Dado um espaço topológico $X$, é possível, em certos casos, construí-lo a partir de espaços topológicos mais simples, no caso bolas euclidianas, também chamadas de n-células (pontos para o caso de dimensão 0, segmentos como bolas/intervalos na reta, discos abertos em $\mathbb{R}^{2}$, e assim por diante).

Primeiramente, começamos com o conjunto $X^{0}$ de 0-células, e identificamos as pontas das 1-células à estrutura anterior $X^{0}$, obtendo um novo conjunto $X^{1}$. Em seguida, identificamos as fronteiras das 2-células ao conjunto $X^{1}$, obtendo um novo espaço $X^{2}$. Indutivamente, dada uma estrutura $X^{n-1}$, identificamos as fronteiras das n-células à estrutura $X^{n-1}$, obtendo um novo espaço $X^{n}$. Esse processo não precisa necessariamente parar em algum $n \in \mathbb{N}$.

Definição 4.22 Para um $C W$-Complexo $X$ de dimensão finita (isto é, cujo processo de identificação de bolas euclidianas termina para algum $n \in \mathbb{N}$ ), definimos a característica de Euler como

$$
\chi(X)=\sum_{i=0}^{n}(-1)^{n} c_{n}
$$

onde $c_{n}$ é o número de $n$-células de $X$.

Um resultado importante nesse sentido é o seguinte

Teorema $4.23 \chi(X)$ é independente da escolha de estrutura de $C W$ Complexo para o espaço $X$.

Demonstrações deste resultado encontram-se em (Hen) (pág. 167) e (Ha) (págs. 146 e 146).

Cada um dos poliedros de Platão é uma estrutura distinta para a esfera $\mathbb{S}^{2}$, mas em todos os casos vemos que $V-E+F=2$. No caso, é importante notar que as células não precisam se limitar a conjuntos "comportados"como nos poliedros, que contém segmentos retos como 1-células e faces regulares como 2-células. Tomando, por exemplo, uma quantidade finita de pontos (0-células) na esfera $\mathbb{S}^{2}$, conectando-os com segmentos esféricos (1-células) de forma a formar um grafo conexo, e em seguida preenchendo as regiões esféricas delimitadas (com 2-células), também obtemos uma estrutura de CWComplexo, para a qual a relação $V-E+F=2$ continua valendo. 


\section{Referências bibliográficas}

[BA] BARROS, A. E ANDRADE, P.. Introdução à geometria projetiva. 1.ed. Rio de Janeiro. SBM, 2010. 4.1, 4.1

[BM] BONDY, J.A E MURTY, U.. Graph Theory. Springer, 2008. 4.4

[CF] CROWELL, R. H.; FOX, R. H.. Introduction to knot theory. Dover, New York, 2008. 1.1, 3.6.9

[Fa] FARY, I.. Sur la courbure totale totale d'une courbe gauche faisant un noeud. Bulletin de la S.M.F., 77:128-138, 1949. 2.2

[Fu] FUSTER, M. C. R.. Convexly generic curves in $\mathbf{R}^{3}$. Geometriae Dedicata, 28:7-99, 1988. 3, 3.4, 3.6.8

[Ha] HATCHER, A.. Algebraic topology. Cambridge University Press, 2001. 4.5

[IS] ISMAILOV, A.; SOLODOV, M.. Otimização Volume 1. Condições de otimalidade, elementos de análise convexa e de dualidade. 3.ed. Rio de Janeiro. IMPA, 2014. 1.3, 1.3

[Mi] MILNOR, J. W.. On the total curvature of knots. Annals of Mathematics, 52(2):248-257, 1950. 2.2

[Pa] PAK, I.. Lectures on discrete and polyhedral geometry. https://www.math.ucla.edu/ pak/geompol8.pdf, 2010. 2

[BF93] BALLESTEROS, J. J. N.; FUSTER, M. C. R.. A four vertex theorem for strictly convex space curves. Journal of Geometry., 46:119-126, 1993. 3.4

[CKKS] CANTARELLA, J.; KUPERBERG, G.; KUSNER, R. B. ; SULLIVAN, J. M.. The second hull of a knotted curve. American Journal of Mathematics, 125:1335-1348, 2003. 2

[Hei] HEIL, E.. Trefoil knots with tritangent planes. Contributions to Algebra and Geometry, 45(2):527-530, 2004. 3.6

[Hen] HENLE, M.. A combinatorial introduction to topology. Dover, New York, 1994. 4.4, 4.5 
[Mun] MUNKRES, J.. Topology, 2nd. ed. Prentice Hall, 2000. 4.2, 4.3

[Mur] MURASUGI, K.. Knot Theory and Applications. Birkhäuser, 1996. 3.6 .9 